\title{
Tuning of a convective gravity wave source scheme based on HIRDLS observations
}

\author{
Quang Thai Trinh ${ }^{1}$, Silvio Kalisch ${ }^{1}$, Peter Preusse ${ }^{1}$, Manfred Ern ${ }^{1}$, Hye-Yeong Chun ${ }^{2}$, Stephen D. Eckermann ${ }^{3}$, \\ Min-Jee Kang ${ }^{2}$, and Martin Riese ${ }^{1}$ \\ ${ }^{1}$ Institute of Energy and Climate Research, Stratosphere (IEK-7), Forschungszentrum Jülich, Jülich, Germany \\ ${ }^{2}$ Laboratory for Atmospheric Dynamics, Department of Atmospheric Sciences, Yonsei University, South Korea \\ ${ }^{3}$ Space Science Division, Naval Research Laboratory, Washington DC, USA
}

Correspondence to: Q. T. Trinh (t.trinh@fz-juelich.de)

Received: 26 October 2015 - Published in Atmos. Chem. Phys. Discuss.: 8 December 2015

Revised: 24 March 2016 - Accepted: 17 May 2016 - Published: 13 June 2016

\begin{abstract}
Convection as one dominant source of atmospheric gravity waves (GWs) has been the focus of investigation over recent years. However, its spatial and temporal forcing scales are not well known. In this work we address this open issue by a systematic verification of free parameters of the Yonsei convective GW source scheme based on observations from the High Resolution Dynamics Limb Sounder (HIRDLS). The instrument can only see a limited portion of the gravity wave spectrum due to visibility effects and observation geometry. To allow for a meaningful comparison of simulated GWs to observations, a comprehensive filter, which mimics the instrument limitations, is applied to the simulated waves. By this approach, only long horizontalscale convective GWs are addressed. Results show that spectrum, distribution of momentum flux, and zonal mean forcing of long horizontal-scale convective GWs can be successfully simulated by the superposition of three or four combinations of parameter sets reproducing the observed GW spectrum. These selected parameter sets are different for northern and southern summer. Although long horizontal-scale waves are only part of the full spectrum of convective GWs, the momentum flux of these waves is found to be significant and relevant for the driving of the QBO (quasi-biennial oscillation). The zonal momentum balance is considered in vertical cross sections of GW momentum flux (GWMF) and GW drag (GWD). Global maps of the horizontal distribution of GWMF are considered and consistency between simulated results and HIRDLS observations is found. The latitude dependence of the zonal phase speed spectrum of GWMF and its change with altitude is discussed.
\end{abstract}

\section{Introduction}

Gravity waves (GWs) significantly impact global circulations by accelerating or decelerating the background wind while dissipating or breaking (e.g., McLandress, 1998; McIntyre, 1998; Kim et al., 2003; Alexander et al., 2010). For example, GWs are important in driving the quasi-biennial oscillation (QBO) (e.g., Dunkerton, 1997; Ern and Preusse, 2009; Alexander and Ortland, 2010; Evan et al., 2012; Ern et al., 2014; Kim and Chun, 2015) and the semiannual oscillation (SAO) (Ern et al., 2015). Moreover, they are assumed to be the main driver of the summer-time branch of the stratospheric Brewer-Dobson circulation (Alexander and Rosenlof, 2003; Fritts and Alexander, 2003) and play a significant role in wind reversals in the mesosphere and lower thermosphere (Lindzen, 1981; Matsuno, 1982; Ern et al., 2013).

GWs are generated by different sources such as orography, convection or spontaneous adjustment of jet streams. In our work, we will focus on convectively generated GWs. Convection excites GWs via diabatic forcing by latent heat release and has long been accepted as one of the most prominent sources, in particular at low latitudes. However, convection itself is parameterized in large-domain models and global models. Even if part of the GW spectrum is resolved, physics assumptions and mathematical formulation of the convective parameterization influence the characteristics of the excited GWs (Kim et al., 2007; Preusse et al., 2014).

In order to represent in global models the important contribution of convectively forced GWs to large-scale circulations, several parameterizations of GWD induced by cumu- 
lus convection have been developed (e.g., Rind et al., 1988; Kershaw, 1995; Chun and Baik, 1998, 2002; Beres et al., 2004; Song and Chun, 2005). In this paper we focus on the convective GW source (CGWS) scheme of Song and Chun (2005). In this CGWS scheme, the spatial scale $\delta x$ and the temporal scale $\delta t$ of the diabatic forcing are free tunable parameters. These scales $\delta x$ and $\delta t$ cannot be determined from theory. Generally, there are two approaches to define these parameters: (1) forward estimation assuming typical scales of clouds or convective systems or (2) by comparing the resulting GW distributions with observations. The primary scale set "MF1" of the Yonsei CGWS scheme (Song and Chun, 2005) has $\delta x=5 \mathrm{~km}$ and $\delta t=20 \mathrm{~min}$. These scales are selected based on mesoscale simulations conducted by Song et al. (2003). The primary scale set MF1 shows good agreement with GW temperature variance (GWTV) from Microwave Limb Sounder (MLS) observations on board the Upper Atmosphere Research Satellite (Choi et al., 2009) and with GW momentum flux from three-dimensional mesoscale simulations (Choi and Chun, 2011). However, MF1 underestimates the GWTV observed by Atmospheric Infrared Sounder (AIRS) on board the Aqua satellite, and therefore an additional scale set MF2 $(\delta x=25 \mathrm{~km}, \delta t=60 \mathrm{~min})$ was added (Choi et al., 2012). GWTV given by the combination of MF1 and MF2 matches AIRS observations well in both horizontal distribution and magnitude. Nevertheless, this combination cannot explain the GW spectrum observed by HIRDLS, which peaks at longer horizontal wavelength of about $600 \mathrm{~km}$ and vertical wavelength of about $10 \mathrm{~km}$ (Ern and Preusse, 2012). A possible reason is that MF1 and MF2 do not describe the presence of large-scale convective systems.

Recently, an increasing number of studies show evidence of the essential contribution of such large-scale convective systems to the global climatology. For example, in the paper of Liu and Zipser (2015), snapshots of precipitation systems (precipitation features (PFs)) observed by the precipitation radar on board the Global Precipitation Mission (GPM) were analyzed. The largest PFs are found with sizes greater than $100000 \mathrm{~km}^{2}$. Liu and Zipser (2015) reported that PFs with sizes greater than $48756 \mathrm{~km}^{2}$ contribute $28 \%$ of total global precipitation. For PFs with size larger than $10000 \mathrm{~km}^{2}$, this contribution is $54 \%$.

In the work of Khouider and Moncrieff (2015) a modified version of a previously developed multicloud model is used for parameterizing mesoscale convective systems (MCSs). For the condition of a typical double African and equatorial jet shear flow, a linear analysis of this modification shows an additional new scale-selective instability with a maximum of approximately $400 \mathrm{~km}$. In addition, in the work of Kilpatrick and Xie (2015), surface wind observations from the Advanced SCATterometer (ASCAT) are utilized to estimate the downdrafts of MCSs. These observations show the existence of MCSs with the scale of 100-300 km.
On one hand, the GW spectra for MF1 and MF2 are not in agreement with the spectra observed by HIRDLS. On the other hand, there is an increasing number of recent studies showing the importance of large-scale convective systems. This indicates a need of finding a new larger scale set for the CGWS scheme, which can correctly reproduce the spectrum observed by limb sounders. For this reason, we determine the free tunable parameters of the CGWS scheme that provide the best agreement with HIRDLS observations in this work. For that purpose a wide range of spatial and temporal scale sets of the CGWS scheme is surveyed. Based on that survey and observations from HIRDLS, combinations of scale sets which best fit the observed GW spectrum are selected for January and July 2006. Although simulations focus on the year 2006, similar convective regions are observed in different years (e.g. Ern et al., 2006, 2011; Alexander et al., 2008) and the current study aims to determine general characteristics of convective GWs by tuning the parameterization based on observations. This will be supported by modelmeasurement comparison of 3 consecutive years. We also introduce an additional tuning parameter that controls the initial wave amplitude and therefore determines breaking levels. Details about this parameter will be explained later in the paper. For this purpose we compare zonal mean cross sections of observed and simulated GWMF and its vertical gradient. Again, the observational filter, which mimics the limitation of the instrument due to visibility effects and observation geometry, is applied to the simulations, and we can investigate the relation between absolute GWMF and GWD. Finally, we consider different source regions in global maps and discuss the interaction of GWs with the background wind employing phase speed spectra of the zonal momentum flux.

Until recently, several papers comparing single sources such as convection with observations have been published. Most of them are either completely theoretical using educated guesses for spectral distributions, or purely observational; some of them show correlations to proxies of deep convection (e.g. McLandress et al., 2000; Jiang et al., 2004; Jia et al., 2014). There are a few studies which compare distributions in the hot spot regions of convective GWs in the summertime subtropics (Choi et al., 2009, 2012). These studies used an educated guess to define the free parameters governing the spectral distribution and confine this guess by the global spatial distribution of GW variances. In our paper, for the first time, the spectral information of global observations is used to confine the spectral distribution in a CGW model. The spatial distributions are then used as an additional test. Furthermore, we estimate the relative importance of convective GWs for the momentum budget in different parts of the world. The step by step approach, confining the parameters first and using these for the global distributions again distinguishes this paper from previous studies.

The paper is organized as follows: in Sect. 2 we introduce the model setup. The systematic survey of different scale sets for the CGWS scheme is shown in Sect. 3. Also in Sect. 3 
zonal mean cross sections of GWMF, its vertical gradient, GW drag as well as global maps and GWMF spectrum in terms of zonal phase speed and latitude are presented. Finally, the summary and discussion are given in Sect. 4.

\section{Model setup}

Simulations are performed for January and July 2006 using three main elements: first, convective GWs are generated using the CGWS scheme developed at Yonsei University (Song and Chun, 2005). The waves are propagated upward using the Gravity wave Regional Or Global RAy Tracer (GROGRAT) (Marks and Eckermann, 1995; Eckermann and Marks, 1997). Finally, a comprehensive observational filter for limb sounders (Trinh et al., 2015) is applied for comparison with HIRDLS observations. These key components of our simulation are each briefly described in a subsection below.

\subsection{Convective gravity wave source scheme}

The Yonsei CGWS scheme is described in detail by Song and Chun (2005) and here only a short summary is given. This analytical model assumes a diabatic forcing region in a three-layer atmosphere. This three-layer atmosphere has a linear wind shear increasing from $U_{0}$ at the surface to $U_{t}$ at an altitude lying between bottom height and top height of the diabatic forcing. Starting from that altitude level, the background wind is constant and equals $U_{t}$. Stability of this three-layer atmosphere is characterized by a piecewise function equaling $N_{1}$ below the cloud top and $N_{2}$ above the cloud top. Momentum flux due to gravity waves is calculated from the cloud top and can be presented as a function of horizontal phase speed:

$$
\begin{gathered}
\bar{M}(c)=-\operatorname{sgn}\left(U_{t}-c\right) \rho_{0} \frac{2(2 \pi)^{2}}{L_{x} L_{t}}\left(\frac{g}{c_{p} T_{0} N_{1}^{2}}\right)^{2} \\
\frac{N_{2}}{\left|U_{t}-c\right|}|X|^{2} \Theta(c) .
\end{gathered}
$$

Here $c$ is the horizontal ground-based phase speed, $\rho_{0}$ is the air density at cloud top, $L_{x}$ and $L_{t}$ are appropriate spatial and temporal scales, respectively, used for averaging, $c_{p}$ is the specific heat of air at constant pressure, $T_{0}$ is the reference temperature at cloud top, $|X|^{2}$ represents resonance between vertical harmonics of natural wave modes and diabatic forcing. $|X|^{2}$ also represents gravity wave filtering by the background wind during vertical propagation up to the cloud top. Therefore, $|X|^{2}$ is referred to as a wave-filtering and resonance factor. In the updated version of the CGWS scheme, Choi and Chun (2011) later redefined $\frac{N_{2}}{\left|U_{t}-c\right|}|X|^{2}$ as the wave-filtering and resonance factor. $\Theta(c)$ is the diabatic source function, which is described as follows:
$\Theta(c)=\frac{2 q_{0}^{2}}{\delta_{x}}\left(\frac{\delta_{x} \delta_{t}}{16 \pi}\right)^{2} \frac{\sqrt{\pi / 2}}{\sqrt{1+\left(c-c_{q}\right)^{2} / c_{0}^{2}}}$,

where $q_{0}$ is the maximum magnitude of the diabatic forcing, $c_{q}$ presents the moving speed of the forcing, and $c_{0}=\delta_{x} / \delta_{t}$, where $\delta_{x}$ and $\delta_{t}$ are spatial and temporal scales of the forcing, respectively. The function $\Theta(c)$ has a maximum at the phase speed equaling to $c_{q}$ and monotonically decreases as $\left|c-c_{q}\right|$ increases (cf. Fig. 6a in Song and Chun, 2005).

The parameters $q_{0}$ and $c_{q}$ as well as the cloud bottom and cloud top height needed to calculate the wave-filtering and resonance factor are determined from MERRA as follows: the vertical configuration of the heating is a 2 nd order polynomial (cf. Eq. 8 of Song and Chun, 2005). Based on that assumption, heating profiles provided by MERRA data are fitted using a second order fit. Cloud top and cloud bottom data from the MERRA data set are used as a first guess for the second order fitting. Results of this second order fit are then used to recalculate top and bottom of the forcing regions. Also, the maximum value of the fitted heating profile between recalculated forcing top and forcing bottom is defined as $q_{0}$. The moving speed $c_{q}$ is determined as the horizontal background wind averaged below $700 \mathrm{mb}$ (Choi and Chun, 2011).

The parameters $\delta_{x}$ and $\delta_{t}$ are free tunable parameters of this CGW source scheme. In this work we perform a systematic survey by running our simulations with different spatial and temporal scales. All the scales used for this survey are shown in the first two columns in Table 1. It should be noted that in previous studies the free input parameters $\delta x$ and $\delta t$ have been defined using educated guesses. In the current work, these parameters are defined using spectral information from observations. Therefore, we first keep an open mind and estimate $\delta x$ and $\delta t$ by adaption to the observed spectrum. A potential physical process related to these $\delta x$ and $\delta t$ values will be discussed later in the paper.

For computational efficiency the momentum flux spectrum $\bar{M}(c)$ is not sampled continuously, but up to 10 maxima in the phase speed range from -100 to $100 \mathrm{~m} \mathrm{~s}^{-1}$ are selected. These discrete values are used as input for the GW ray tracer, launched at the cloud top, and propagated away from the source. Shallow heating depths are not effective in exciting far-propagating GWs. Therefore, simulations are run only for heating depths equal or larger than $3.5 \mathrm{~km}$. When coupling the GW ray tracer to the CGWS scheme, there is a further tuning potential to adapt the global distributions. We can reduce the launch amplitude by a factor of $1 / \sqrt{\alpha}$ and simultaneously multiply the number of launched rays by a factor of $\alpha$. In this way we retain the same total GWMF at launch but reduce the amplitude of the individual waves. This may be interpreted by spreading the same total GWMF over a larger area, i.e., assuming that the wave packet has a larger spatial extent. An important consequence is that by reducing the 
Table 1. Surveyed and selected spatial and temporal scales $(\delta x, \delta t)$ as well as intermittency factor $(\zeta)$ for the Yonsei CGWS scheme. Spectra corresponding to the values given in bold are shown in Fig. 1.

\begin{tabular}{|c|c|c|c|c|c|c|c|}
\hline \multicolumn{2}{|c|}{ Scales used for surveying } & \multicolumn{3}{|c|}{ Selected scales for January } & \multicolumn{3}{|c|}{ Selected scales for July } \\
\hline$\delta x(\mathrm{~km})$ & $\delta t(\min )$ & $\delta x(\mathrm{~km})$ & $\delta t(\min )$ & $\zeta$ & $\delta x(\mathrm{~km})$ & $\delta t(\min )$ & $\zeta$ \\
\hline 4 & 10 & 80 & 240 & 1.0 & 40 & 80 & 1.0 \\
\hline 8 & 20 & 120 & 120 & 0.4 & 160 & 100 & 1.0 \\
\hline 12 & 40 & 200 & 150 & 0.4 & 250 & 240 & 1.0 \\
\hline 25 & 80 & 250 & 360 & 0.7 & & & \\
\hline 40 & 120 & & & & & & \\
\hline 80 & 240 & & & & & & \\
\hline 120 & 360 & & & & & & \\
\hline 250 & 720 & & & & & & \\
\hline 400 & & & & & & & \\
\hline 800 & & & & & & & \\
\hline 1200 & & & & & & & \\
\hline
\end{tabular}

amplitude of the individual waves, saturation is reached at higher altitudes in the atmosphere.

The vertical profile of latent heat release is taken from three-hourly MERRA (modern-era retrospective analysis for research and applications) assimilated data, which use a parameterization for convection. The chief aim of the parameterization is to capture the total amount of rain and the vertical redistribution of water. That should confine the vertical structure of latent heat release. This is the only explicit input we require from MERRA for our study. Spatial and temporal scales of the convection are formulated in the CGWs scheme as described above. More detailed information about MERRA data as well as convective parameterization in MERRA can be found, for example, in Rienecker et al. (2011), Kim and Alexander (2013) and Wright and Fueglistaler (2013).

\subsection{The gravity wave ray tracer}

In the current work, propagation of GWs from convective GW sources into the middle atmosphere is performed using GROGRAT. Details about this ray tracer are presented in Marks and Eckermann (1995) and Eckermann and Marks (1997). We here only give a brief description. GROGRAT is based on the full gravity wave dispersion relation, which includes both non-hydrostatic gravity waves and the Coriolis force. Wave packets are propagated according to the local group velocity of the wave depending on the wave vector and intrinsic frequency. The ray-tracing equations (Lighthill, 1967) are solved using a 4th order Runge Kutta integrator. The integration comprises the calculation of refraction of the wave vector caused by gradients of the atmospheric background in both vertical and horizontal directions. Wave action is calculated along the wave trajectory accounting for dissipation, damping, and saturation processes. Amplitude damping caused by turbulence is calculated following the work of Pitteway and Hines (1963). Radiative damping due to the temperature difference between warm and cold phases of the wave is considered following Zhu (1994). The saturated amplitude of the wave is limited using saturation criteria of Fritts and Rastogi (1985). Moreover, MERRA winds and temperature are used as atmospheric background for the ray-tracing calculations.

\subsection{The comprehensive observational filter for satellite limb sounders}

For comparing modeled results with HIRDLS observations, a comprehensive observational filter for satellite infrared limb sounding of gravity waves was applied. Details of this observational filter are described in Trinh et al. (2015). The observational filter considers both the visibility of waves to an infrared limb sounder and a sophisticated representation of the observation geometry. The absolute GWMF simulated by applying this observational filter to the model results can be directly compared to the GWMF from observed temperature amplitudes (Ern et al., 2004):

$F=\frac{1}{2} \rho \frac{\lambda_{z}}{\lambda_{h}}\left(\frac{g}{N}\right)^{2}\left(\frac{\hat{T}}{T}\right)^{2}$

where $F$ denotes absolute GWMF, $\rho$ is the background atmosphere density, $\lambda_{z}$ and $\lambda_{h}$ are vertical and horizontal wavelengths, respectively, $g$ denotes the gravity acceleration, $N$ is the buoyancy frequency, $T$ is the background temperature and $\hat{T}$ is the temperature amplitude of the wave. Although Eq. (3) is based on a monochromatic wave assumption while CGWs are a multiscale problem, it was shown that in a statistical sense, spectra of CGWs obtained from 2-D Fourier transform can be well reproduced using a single-wave approach (Lehmann et al., 2012). Furthermore, our modeling approach is based on a number of discrete waves, which enhances compatibility between the two approaches. We thus 
expect that no larger biases will be introduced by the chosen approach.

The observational filter comprises four main processes: (1) visibility filter, (2) projection of the wavelength on the tangent-point track, (3) aliasing effect, and (4) calculation of the vertical observed wavelength. The first process (visibility filter) considers impacts caused by radiative transfer and retrieval (Preusse et al., 2002). This visibility filter directly influences the temperature amplitude $\hat{T}$. From HIRDLS observations information is provided only along measurement track. The horizontal wavelength along measurement track is generally larger than the real horizontal wavelength. The second process of the observational filter determines this alongtrack wavelength and the associated reduction of GWMF by modifying $\lambda_{h}$ in Eq. (3). The aliasing effect (the third process) estimates the projection of waves towards much longer wavelengths by aliasing and the corresponding reduction of GWMF. Due to the aliasing effect, $\lambda_{h}$ in Eq. (3) may have a larger value and accordingly, $F$ may decrease. The calculation of the vertical observed wavelength (the fourth process) addresses effects of non-vertical altitude profiles. Due to this effect, not only the vertical structure of an observed wave is sampled, but also to some extent the horizontal structure. The vertical wavelength $\lambda_{z}$ in Eq. (3) therefore should be recalculated by considering this effect. Finally, additional corrections are applied that are required for the real satellite data to remove dominant vertical oscillation of quasi-stationary planetary waves as well as to keep only those vertical wavelengths for which amplitudes can reliably be determined in the $10 \mathrm{~km}$ vertical window of the MEM/HA spectral analysis (Preusse et al., 2002; Ern et al., 2011).

\section{Results}

\subsection{A systematic survey of the Yonsei CGWS scheme}

The purpose of this systematic survey is to find sets of free parameters $\delta x$ and $\delta t$ which describe spectra in terms of horizontal and vertical wave numbers observed by HIRDLS. For the systematic survey of the spatial and temporal scales we tested the whole set of combinations given by the surveyed scales in the first two columns in Table 1. These scales are selected on one hand to cover the whole potential ranges, on the other hand with the appropriate step width to minimize the number of different scales and therefore to improve the computational efficiency. An appropriate step width also helps to distinguish the changing of the spectrum in the base 10 logarithmic scale of the wave numbers.

Figure 1 provides an overview of the results for a reduced set of filtered, simulated GW spectra. In Fig. 1, for a better visualization, only spectra corresponding to the values given in bold in Table 1 are shown. Spectra in Fig. 1 are shown for July 2006 at the altitude of $25 \mathrm{~km}$ and averaged over the same regions defined as deep convection (DC) regions in Ern and
Preusse (2012). The location of these regions is indicated in Fig. 2; regions for boreal summer (Northern Hemisphere) are marked in red, regions for austral summer (Southern Hemisphere) are marked in green. The spectra in Fig. 1 are generated by binning absolute GWMF from ray-tracing calculations according to horizontal and vertical wave numbers $\left(k_{h}\right.$ and $m$ ) using a technique similar to that of Ern and Preusse (2012). The base 10 logarithmic scale is employed here, i.e., the $x$ axis shows $\widetilde{k_{h}}=\log _{10}\left(1 / \lambda_{h}\right)$ while the $y$ axis shows $\widetilde{m}=\log _{10}\left(1 / \lambda_{z}\right)$. Here $\lambda_{h}$ and $\lambda_{z}$ denote the horizontal and vertical wavelengths, respectively. The sizes of each bin in $x$ and $y$ direction are $\delta \widetilde{k_{h}}=0.1$ and $\delta \widetilde{m}=0.1$.

In Fig. 1 the color shading represents the GWMF spectra simulated by the Yonsei CGWS, propagated to observation altitude by GROGRAT and filtered according to the comprehensive observational filter. The dashed contour lines indicate the spectrum observed by HIRDLS for regions of deep convection (Ern and Preusse, 2012). For the model spectra, spatial scale increases from the right column to the left column in Fig. 1. The temporal scale increases from the bottom to the top in Fig. 1. As shown by Fig. 1, the horizontal wavelength of the spectral peak increases as the spatial scale $\delta x$ of the convective system increases. Due to the resonance effect formulated in the CGWS scheme, the phase speeds and hence the vertical wavelength of the spectral peak depends only weakly on the temporal scale $\delta t$ of the convective system. We hence use the observed spectra to (a) gain information on the horizontal scale, which is not determined by the model conception, and (b) to validate the vertical wavelength spectrum. This is a corroboration of the model assumptions. The comparison of the spectrum hence is a confirmation that the basic assumptions of the model describe reality well, at least in a statistical sense.

It can also be seen in Fig. 1 that GWs forced by convective systems with very short spatial and temporal scales (e.g., Fig. 1n, o, s, t) are strongly suppressed in HIRDLS observations due to the observational effect. Some of the spectra (e.g., Fig. 1g, h, 1) show a spectral peak, which locates closely to the observed spectral peak. To complement the survey grid with a parameter set providing a close match with the observed spectral peak, we calculated additional spectra with $\delta x=200 \mathrm{~km}$ and $\delta t=150 \mathrm{~min}$ for January 2006 and $\delta x=160 \mathrm{~km}$ and $\delta t=100 \mathrm{~min}$ for July 2006 .

As mentioned in the introduction, the large-scale convective system studies (Liu and Zipser, 2015; Khouider and Moncrieff, 2015; Kilpatrick and Xie, 2015) indicate that CGW forcing is a multi-scale problem with major contributions by a few dominant scales. For this reason we combine several spectra from the systematic survey in order to obtain a best fit to the observed spectra. Spectra are super-imposed by minimizing the following function:

$\eta=M_{\mathrm{obs}}-\sum_{i} \zeta_{i} M_{i} / \sum_{i} \zeta_{i}$ 

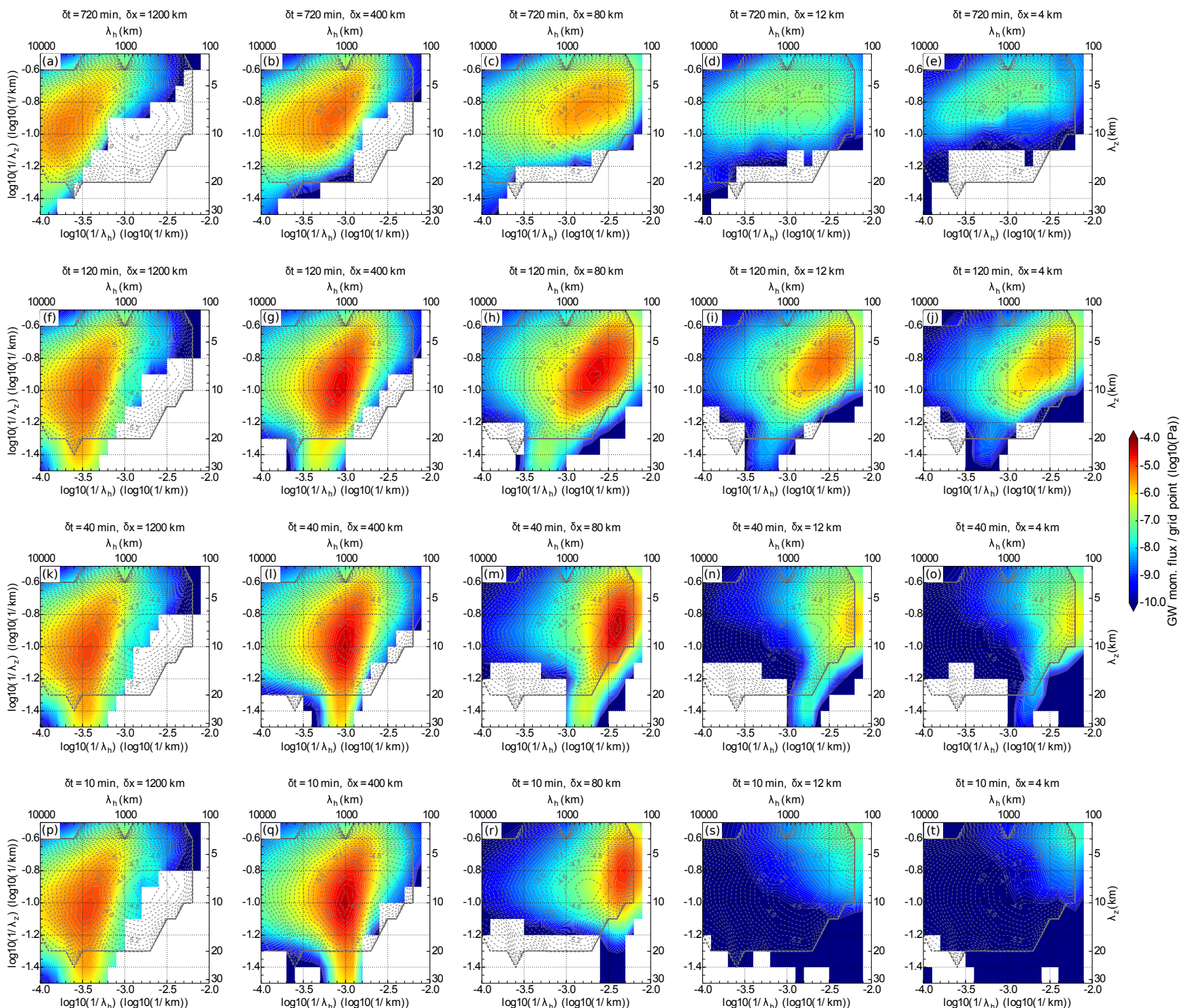

Figure 1. A systematic survey of the CGWS scheme depending on different spatial and temporal scales of the convective system for July 2006. The color code shows the simulated GWMF spectra of CGWs generated by the Yonsei CGWS scheme, propagated upward to $25 \mathrm{~km}$ altitude using GROGRAT and filtered according to the observational filter. The dashed contour lines show the spectrum for regions of deep convection observed by HIRDLS.

where $M_{i}$ is a single spectrum from the systematic survey, $\zeta_{i}$ is the respective intermittency factor, and $M_{\mathrm{obs}}$ is the observed GWMF spectrum. Combinations of $M_{i}$ with respective $\zeta_{i}$, which give the best fit to the observed spectrum, are chosen from minimization of $\eta$ and shown in Fig. 3c for January and Fig. 3d for July 2006. For computational efficiency, we limit the maximum number of combined spectra to 4 and only largest $\zeta_{i}$ are selected. The selected spatial scale $\delta x$, temporal scale $\delta t$ as well as corresponding intermittency factor $\zeta$ are shown in Table 1 for January and July 2006. As shown by Fig. $3 \mathrm{c}$ and d, the filtered simulated spectrum matches the observed spectrum very well in both shape and location of the spectral peak for both conditions of January and July 2006. The scales selected by our approach quantitatively agree well with those found in the convective system studies, which were mentioned in the introduction.

Moreover, it is noteworthy that different combinations of scale sets are needed for January and July (cf. Table 1). This leads to a question: is the difference between January and July 2006 caused by a persistent difference between the two hemispheres or is it caused by the temporal variability of convective source processes? In order to investigate this question we have considered spectra for 3 consecutive years. This is described in Appendix A. In summary, we find a general 


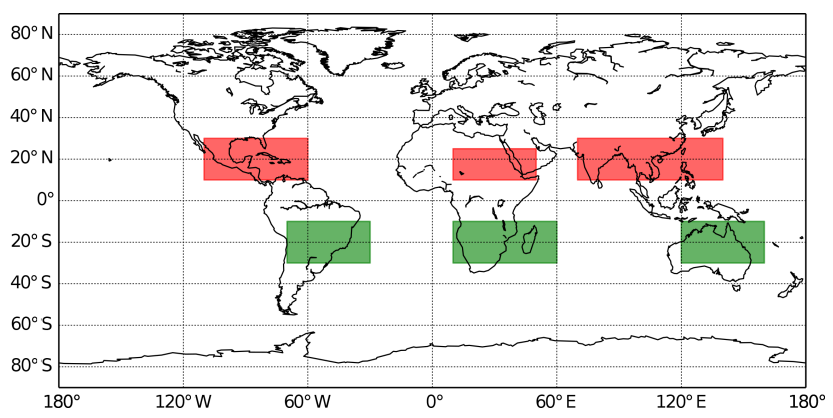

Figure 2. Regions of deep convection. For the Northern Hemisphere, three regions of deep convection are demonstrated by three red rectangles. For the Southern Hemisphere, three regions of deep convection are indicated by three green rectangles.

tendency for longer horizontal wavelengths in the Southern Hemisphere caused by different source characteristics. We also find a modulation of the GW spectrum at $25 \mathrm{~km}$ altitude likely due to the QBO which can be reproduced with the same set of model parameters. This indicates that the QBO modulation is caused primarily by different propagation conditions of the GWs.

In addition, in order to demonstrate effects of the observational filter, we show unfiltered combined spectra of the same selected scale sets for January 2006 in Fig. 3a and for July 2006 in Fig. 3b. Comparison of Fig. 3a, b and Fig. 3c, d shows that the observational filter not only reduces the magnitude, but also significantly changes the shape of the spectrum. In particular, contributions of short horizontal wavelength waves as well as short vertical wavelength waves strongly decrease and are also partly shifted to longer horizontal wavelengths. More details about effects of the observational filter on GW spectrum can be found in Trinh et al. (2015).

\subsection{Zonal average of convective GWMF and its vertical gradients}

In Sect. 3.1 the free parameters of the convective source scheme were estimated. In this section, we apply these parameters to global-scale simulations in order to estimate the effect of CGWs on the global distribution of GWMF and GW drag. There are limitations to our approach: the selected scales are determined in regions that are likely dominated by GWs that are excited by deep convection (see Fig. 2 for regions of deep convection). However, in regions which are not dominated by one source process, we cannot sort the observed waves according to sources, at least not based on current limb sounding observations. Comparison between observed and modeled spectra thus does not provide a meaningful constraint on the CGW source scheme parameters. Therefore the constraint from the regions of deep convection is the only observational guidance we have and which we consider preferential to a guess. Accordingly, in order to study the im-
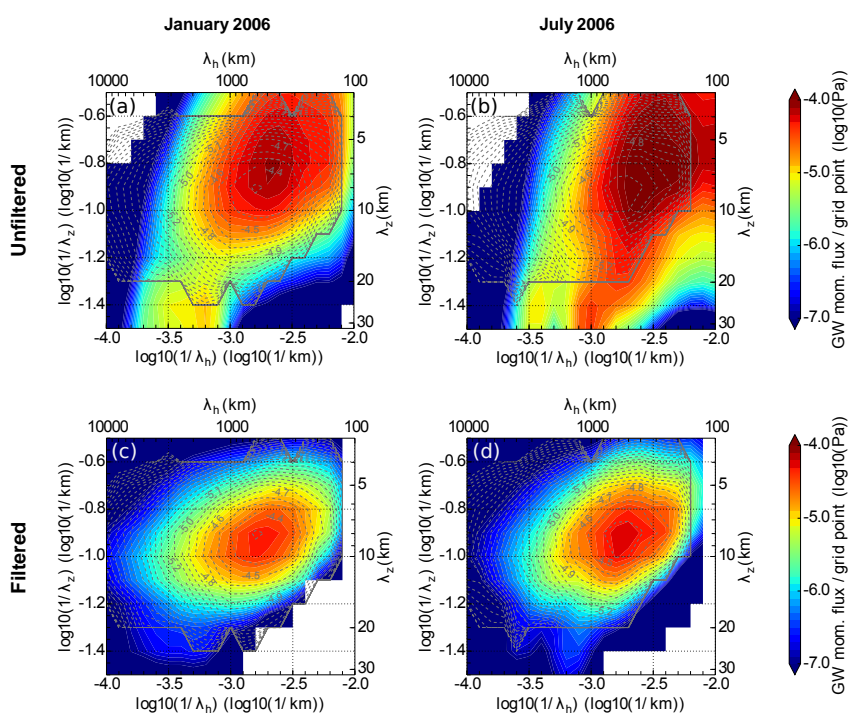

Figure 3. Unfiltered combined GW spectra of selected scale sets for (a) January 2006 and (b) July 2006 and filtered combined spectra of selected scale sets for (c) January 2006 and (d) July 2006. All spectra are shown for the altitude level of $25 \mathrm{~km}$. The color code represents combined filtered simulated spectra; the dashed contour lines represent spectra observed by HIRDLS for regions of deep convection.

portance of CGWs on a global scale, the selected sets of $\delta x$ and $\delta t$ are used globally for the convective sources for January and July, respectively.

Zonal averages of GWMF and its vertical gradient are calculated and shown in Fig. 4 for January and in Fig. 5 for July 2006. In all panels of Figs. 4 and 5, contour lines indicate zonal average zonal wind for the respective month. In order to generate zonal averages of absolute GWMF, the values from ray-tracing calculations are first binned onto a three-dimensional grid with bin sizes of $10^{\circ}$ in longitude, $2^{\circ}$ in latitude and $1 \mathrm{~km}$ in altitude. Results are normalized by total number of rays and the zonal averages are calculated.

Figures $4 \mathrm{a}$ and 5a show simulated absolute GWMF without observational filter effects for January and July, respectively. Unfiltered GWMF shown in Figs. 4a and 5a is calculated as $F_{p h}=\sqrt{F_{p x}^{2}+F_{p y}^{2}}$, where $F_{p x}$ and $F_{p y}$ are GWMF components in zonal and meridional direction, respectively, as determined from the ray-tracing calculations. Both Figs. 4a and 5a show a main maximum of GWMF in the summer subtropics spreading from the equator to about $25^{\circ} \mathrm{S}$ (Fig. 4a) or to about $25^{\circ} \mathrm{N}$ (Fig. 5a), which is consistent with the latitude band of deep convection (e.g. Jiang et al., 2004). The width and magnitude of this maximum decreases with altitude due to wave dissipation, wave breaking and wind filtering. For January, this decrease is significant and strongly related to wind filtering at the altitude of about $20 \mathrm{~km}$, where GWs encounter a wind reversal. 

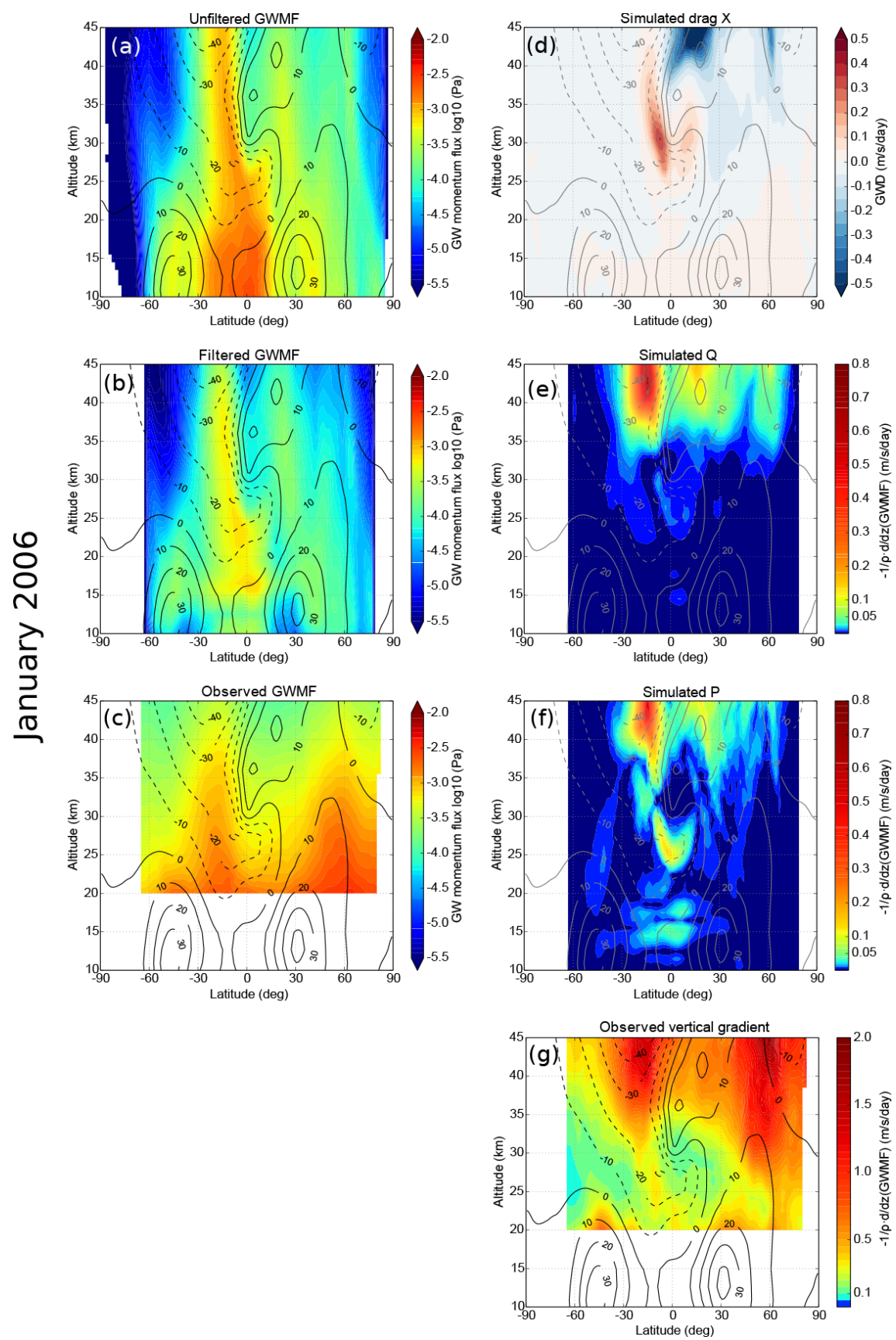

Figure 4. Comparison of simulated GWMF and its vertical gradients with observations from HIRDLS for January 2006. Panel (a) shows simulated unfiltered absolute GWMF. Panel (b) shows simulated filtered absolute GWMF. Panel (c) shows absolute GWMF observed by HIRDLS. Panel (d) shows simulated zonal GW drag. Panel (e) shows simulated vertical gradient $Q$. Panel (f) shows simulated vertical gradient $P$. Panel (g) shows observed vertical gradient of absolute GWMF from HIRDLS. Simulations were performed using MERRA data. For details see text.

Figures $4 \mathrm{~b}$ and $5 \mathrm{~b}$ show filtered, simulated absolute GWMF for January and July, respectively. Due to the observational filter the magnitude of GWMF is reduced by about half an order of magnitude.

Observed GWMF from HIRDLS for January and July are shown in Figs. $4 \mathrm{c}$ and $5 \mathrm{c}$, respectively. It should be noted that observations from HIRDLS shown in Figs. 4 and 5 contain global data of all regions, not only the regions of deep convection. For comparing filtered, simulated GWMF (Figs. 4b, $5 b$ ) with observed GWMF (Figs. 4c, 5c) it is very important to keep in mind that the model results show GWMF only from convective sources, while observations from HIRDLS 

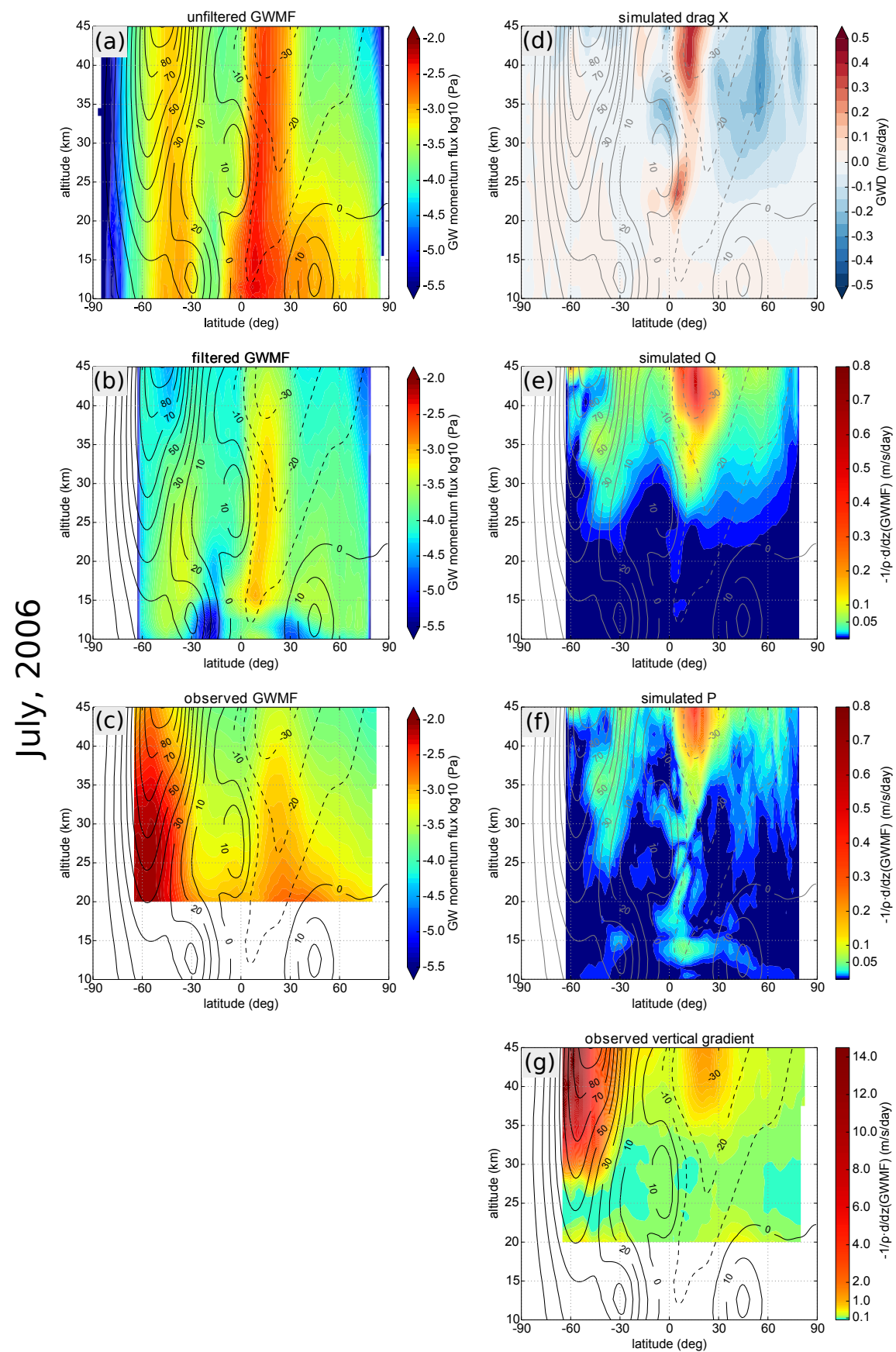

Figure 5. Comparison of simulated GWMF and its vertical gradients with observations from HIRDLS for July 2006. Panel (a) shows simulated unfiltered absolute GWMF. Panel (b) shows simulated filtered absolute GWMF. Panel (c) shows absolute GWMF observed by HIRDLS. Panel (d) shows simulated zonal GW drag. Panel (e) shows simulated vertical gradient $Q$. Panel (f) shows simulated vertical gradient $P$. Panel (g) shows observed vertical gradient of absolute GWMF from HIRDLS. Simulations were performed using MERRA data. For details see text.

contain GWMF from a variety of sources. As convection is believed to dominate the summer subtropics, we expect model and observations to better match at low latitudes. At mid and high latitudes HIRDLS observations indicate an enhancement, likely due to other sources. Considering these facts, the simulated maximum in Fig. $4 \mathrm{~b}$ and the secondary maximum in Fig. 4c in the summer subtropics match well. The same agreement can be seen by comparing Fig. $5 \mathrm{~b}$ and c. In particular, centers of these maxima are both located at about $15^{\circ} \mathrm{S}$ for austral summer (Fig. $4 \mathrm{~b}, \mathrm{c}$ ) or at about $15^{\circ} \mathrm{N}$ for boreal summer (Fig. 5b, c). Also, the structure of these maxima in the tropics from about 20 to about $40 \mathrm{~km}$ altitude 
in both simulations and observations follow the contour line of the wind reversal. However, the magnitude of the simulated maximum is somewhat lower than the observed one. Moreover, the width of the simulated maximum is slightly narrower than the observed one. The weaker and narrower peak in the simulations could indicate that deep convection is spread over a wider latitude range than simulated in MERRA or that we need to revisit the forcing efficiency. However, there are also indications from radiosonde and ground-based measurements (e.g. Leena et al., 2012; Pramitha et al., 2015) and modeling (e.g. Preusse et al., 2014) that in the regions of deep convection GWs are excited around tropopause altitude. Details of that GW excitation are not fully understood, but they are presumably associated with the shear and strong buoyancy change present at these altitudes. These waves seem to be less focused to the convective regions and produce a substantial background outside the selected convection regions used for the spectra (cf. Figs. 4c and 5c) and thus potentially become important in the zonal means. At high winter latitudes, CGWs contribute only a minor part of the total GWMF. This can be seen from the unfiltered GWMF values as well.

\subsubsection{Different measures of the vertical gradient}

Vertical cross sections of the absolute value of GWMF span several orders of magnitude and accordingly a logarithmic color scale is used, which emphasizes the major features while the precise vertical structure is difficult to discern. On the other hand, for discussing the interaction of GWs with the background flow it is important to consider the exerted zonal mean drag in the zonal direction. We calculate the drag by calculating the vertical change of zonal momentum flux along the ray. In this way the calculations take into account wave dissipation and horizontal refraction but do not cause a spurious acceleration where GWs just propagate horizontally out of a region where we calculate the vertical gradient. The zonal mean drag in the zonal direction is calculated as follows:

$X=-\left\langle 1 / \rho \cdot \frac{\partial}{\partial z} F_{x}\right\rangle$,

where $\rho$ is atmospheric density, $F_{x}$ is the zonal GWMF and \langle\rangle denotes the zonal mean. Unfortunately measurements can provide only vertical gradient $P$ :

$P=-\left\langle 1 / \rho \cdot \frac{\partial}{\partial z}|\Omega(\boldsymbol{F})|\right\rangle$,

where $\boldsymbol{F}$ is the horizontal vector of GWMF, $\Omega$ denotes the observational filter and || denotes absolute values in 2-D, i.e., here $\sqrt{\Omega\left(F_{x}\right)^{2}+\Omega\left(F_{y}\right)^{2}}$, where $F_{y}$ is the meridional GWMF. In fact, differences between $X$ and $P$ can be significant: waves dissipating, because they reached saturation amplitudes, but propagating in opposite directions cancel each other when calculating $X$ but contribute both positively in calculating $P$. Moreover, waves propagating conservatively but moving out of the observational filter $\Omega$ will enhance $P$ but they do not contribute to the real drag $X$. Therefore, $P$ may exhibit different patterns from $X$. However, $P$ still emphasizes the vertical gradient and in this respect it is the closest proxy for $X$ we can gain from measurements. The model setup of this paper allows us to calculate both $X$ and $P$ and hence to compare $P$ to the observations. Furthermore, we can study the various contributions of dissipation, drag and observational filter by calculating different combinations of the vertical derivative, the observational filter and the absolute value.

\subsubsection{Physical interpretation:}

Figures 4d and 5d show the simulated zonal drag $X$ for January and July 2006 , respectively. In the tropics $\left(15^{\circ} \mathrm{S}-\right.$ $15^{\circ} \mathrm{N}$ ), in the lower and mid-stratosphere (i.e., up to about $35 \mathrm{~km}$ ) drag is exerted in regions of vertical wind shear. There we find positive drag for positive shear and negative drag for negative shear as expected for the driving of the QBO. Moreover, the magnitude of the simulated zonal drag $X$ is comparable to the "missing drag" deduced in Ern et al. (2014). In Ern et al. (2014), in order to estimate the QBO driving by GWs, the transformed Eulerian mean zonal momentum equation (Andrews et al., 1987) was utilized. All terms of this equation except the drag due to GWs were calculated using ERA-Interim assimilated data (Dee et al., 2011). The drag due to GWs is then deduced based on this equation and other calculated terms and is referred to as the "missing drag". In addition, for January 2006, Fig. 4d shows a particularly noteworthy U-shaped structure at the altitudes of around $30 \mathrm{~km}$.

The closest similarity to observed potential drag is provided by $P$, which takes into account reduction of observed GWMF both by dissipation and by the fact that waves are moving out of the observational filter. In order to distinguish between these two processes we introduce a further quantity which shows only the true dissipation we observe. Figures $4 \mathrm{e}$ and 5e show another type of vertical gradient of GWMF, which is calculated as follows:

$Q=-\left\langle 1 / \rho \cdot\left|\Omega\left(\frac{\partial}{\partial z} \boldsymbol{F}\right)\right|\right\rangle$.

The vertical gradient $Q$ only considers the dissipation caused by those waves which are visible to the instrument. This also means that dissipation of waves which are not seen by the instrument is not taken into account in $Q$ even though these waves exert real drag and are taken into account in calculating $X$. In Fig. 4e the U-shaped structure is much less pronounced in comparison with Fig. $4 d$, which indicates that the drag is exerted when the waves attained very short vertical wavelength and are already removed by the observational filter from $Q$. Such short vertical wavelengths would also mean that critical level filtering is an important process in this region. 
In both Fig. 4e and d, strong dissipation can be seen for a wind maximum at $40-45 \mathrm{~km}$ altitude and $20^{\circ} \mathrm{S}$, which is located above the strongest sources. The maximum is similarly strong in $Q$ and in $P$ indicating that observational filter effects are less important. This is the case for waves with vertical wavelengths longer than the short-wavelength edge of the observational filter. This also means that critical level filtering is not relevant at this point. For longer vertical wavelengths, dissipation may be reached just by the exponential amplitude growth which compensates the decrease of atmospheric density. This is particularly likely in regions where GW amplitudes are large already at excitation level. The net drag in Fig. 4d is low indicating that waves from both propagation directions contribute, which is compatible with saturation by amplitude growth. A small preferential net drag in this case is caused by a preferential direction in GWMF. Similar strong dissipation can be seen at the same altitude range at about $20^{\circ} \mathrm{N}$ in Fig. $5 \mathrm{~d}$ and e. Here the preference in propagation direction and net drag are considerably stronger. This dissipation in the upper stratosphere is important for the driving of the SAO in the tropics (cf. discussion in Ern et al., 2015).

Figures $4 \mathrm{f}$ and $5 \mathrm{f}$ show simulated $P$ (the quantity observations should be compared to). For January, both the U-shaped structure at around $30 \mathrm{~km}$ and the maximum above $40 \mathrm{~km}$ are visible and correspond well to similar structures in the observed vertical gradient from HIRDLS (Fig. 4g). In Fig. 4d and $\mathrm{f}$, the $\mathrm{U}$-shaped structure is more pronounced than in Fig. 4e. A possible reason for this difference is the following: in the U-shaped structure we presumably see many waves of low horizontal phase speeds which are refracted to very short vertical wavelengths and therefore are not visible to the satellite instrument. As the saturation is reached only when the vertical wavelength is even shorter than the short edge of the visibility filter, these waves propagating from below first do not pass the observational filter any longer (absence in Fig. $4 \mathrm{f}$ at $30 \mathrm{~km}$ altitude and $15^{\circ} \mathrm{N}$ ) but dissipate almost immediately above (Fig. $4 \mathrm{~d}$ at $30-33 \mathrm{~km}$ and $15^{\circ} \mathrm{N}$ ). The dissipation itself is then not visible to the satellite (low values of vertical gradient at $30-33 \mathrm{~km}$ and $15^{\circ} \mathrm{N}$ in Fig. 4e). It should be mentioned that a related shift in the altitude of observed GWD has been discussed in Ern et al. (2014).

As we mentioned in Sect. 2.1, further tuning is achieved by reducing the launch amplitude by a factor of $1 / \sqrt{\alpha}$ and simultaneously multiplying the number of launched rays by a factor of $\alpha$. In this study $\alpha$ is chosen to be 5. The choice of $\alpha$ does not affect the total GWMF at launch but can affect GWMF aloft, shifting the saturation level to different altitudes. Therefore, depending on the choice of $\alpha$ structure and magnitude of GWMF, zonal drag, simulated $P$, and simulated $Q$ may be altered. With a more detailed consideration of the momentum balance this tuning factor may need to be revisited.

The GW drag maximum at 40 to $45 \mathrm{~km}$ altitude is seen in Fig. 4e, $\mathrm{f}$ and $\mathrm{g}$, but not in Fig. 4d. This is likely caused by longer vertical wavelength waves having gained saturation amplitude but not causing much net GW drag as different propagation directions contribute. In July we find closer correspondence between $P$ and $X$ (again with some altitude shift). The structures of $P$ and $X$ also agree quite well with the structures of observed vertical gradients shown in Fig. $5 \mathrm{~g}$. Similar to GWMF, the observed vertical gradients in Figs. $4 \mathrm{~g}$ and $5 \mathrm{~g}$ are dominated, in particular at higher latitudes, by signatures from sources other than convection. It should also be noted that a $10 \mathrm{~km}$ vertical analysis interval is used for HIRDLS data analysis, which could also lead to some differences between model results and observations.

The results presented in this section show good general agreement between modeled and observed GWMF and potential drag (i.e., vertical gradient of absolute GWMF). This raises confidence in studies investigating the momentum balance of global-scale wind fields such as the QBO (Ern et al., 2014) or SAO (Ern et al., 2015) where scales are concerned that limb sounders can observe. However, the systematic survey of spectra shows that there are source scales which cannot be addressed by limb sounders, for instance the parameter choice associated with MF1. These shorter scales have the potential to carry larger momentum flux at a higher saturation threshold, as the saturation threshold is proportional to the horizontal wavenumber of the waves. This and a potentially different phase speed distribution in such unconfined scales might allow to convey GWMF to higher altitudes and hence contribute to explain differences in the vertical gradient of GWMF between limb-sounding observations and parametrizations employed in GCM (Geller et al., 2013).

\subsection{Horizontal distribution of GWMF and phase speed spectrum}

In this section we show horizontal distributions of simulated convective GWMF as well as spectra of GWMF in terms of zonal phase speed and latitude. In Figs. 6 and 7 data for January, and in Figs. 8 and 9 data for July are shown. Figures 6 and 8 give values for $25 \mathrm{~km}$ altitude, while Figs. 7 and 9 give values for $40 \mathrm{~km}$ altitude. In each of these figures, the left column contains global maps of GWMF: panel a the unfiltered, simulated GWMF, panel $c$ the filtered, simulated GWMF and panel e the observed GWMF. The right column shows zonal GWMF as a function of zonal phase speed and latitude (hereafter referred to as phase speed spectra) in bins of $4 \mathrm{~m} \mathrm{~s}^{-1}$ and $4^{\circ}$. For both maps and spectra the color scales indicate the base 10 logarithm of GWMF. As for phase speed spectra GWMF with negative (westward) phase velocities is negative (westward GWMF), these values were multiplied by -1 before applying the logarithm. HIRDLS does not provide a propagation direction and accordingly phase speed cannot be deduced from the measurements.

In the global maps (panels a, c, e), the rectangle indicated by the magenta dashed line shows the low-latitude area, where convection is assumed to dominate. Blank areas in 



Figure 6. Horizontal distribution of (a) unfiltered absolute GWMF and (c) filtered absolute GWMF in comparison with (e) horizontal distribution of observed absolute GWMF. Panel (b) shows phase speed spectrum of unfiltered zonal GWMF (absolute values) and (d) shows phase speed spectrum of filtered zonal GWMF (absolute values). In phase speed spectra, GWMF values associated with negative values of phase speed (on the left-hand side) are multiplied with -1 . Results are shown for January 2006 at $25 \mathrm{~km}$ altitude. Simulations were performed using MERRA data. For details see text.

panels a, c, e refer to values of GWMF, which are out of the shown value range $\left(<-5.0\left(\log _{10} \mathrm{~Pa}\right)\right.$ or $\left.>-1.0\left(\log _{10} \mathrm{~Pa}\right)\right)$. In panels $b, d$, the gray thick line indicates zonal mean of zonal wind at the considered altitude level, magenta plus line shows maximal zonal mean of zonal wind in the altitude range from cloud top to the considered altitude level, and magenta dot line shows minimal zonal mean of zonal wind in the same altitude range.

For January 2006 , at $25 \mathrm{~km}$ altitude, high values of unfiltered GMWF are found over central south America, south Africa, a strip spreading from Madagascar to Indonesia, Indonesia and north Australia, and a strip over the Pacific ocean at around $20^{\circ} \mathrm{S}$ latitude spreading from 180 to $120^{\circ} \mathrm{W}$ (Fig. 6a). After applying the observational filter, GWMF decreases by about half an order of magnitude (Fig. 6c). In addition, the observational filter also changes the distribution of GWMF at some locations. For example, over the Indonesian region, a band of high GWMF at about $10^{\circ} \mathrm{N}$ spreading from the Philippines to $180^{\circ} \mathrm{E}$, is decreased stronger in comparison with the band of high GWMF at about $0-10^{\circ} \mathrm{S}$. Figure 6e shows observed GWMF from HIRDLS. Comparison of filtered GWMF (Fig. 6c) and observed GWMF (Fig. 6e) shows quite a good agreement in location of GWMF peaks in the summer subtropics. In particular, the maxima over central south America, south Africa, Indonesia and north Australia are reproduced. The magnitude of filtered GWMF is lower in comparison with observed GWMF which, as discussed above, can be explained by a lack of other sources than convection.

The phase speed spectrum for January 2006 at $25 \mathrm{~km}$ altitude (Fig. 6b) shows a major peak in the tropics with eastward phase speed from several $\mathrm{m} \mathrm{s}^{-1}$ to about $25 \mathrm{~m} \mathrm{~s}^{-1}$, with 
Jan $2006, z=40 \mathrm{~km}$
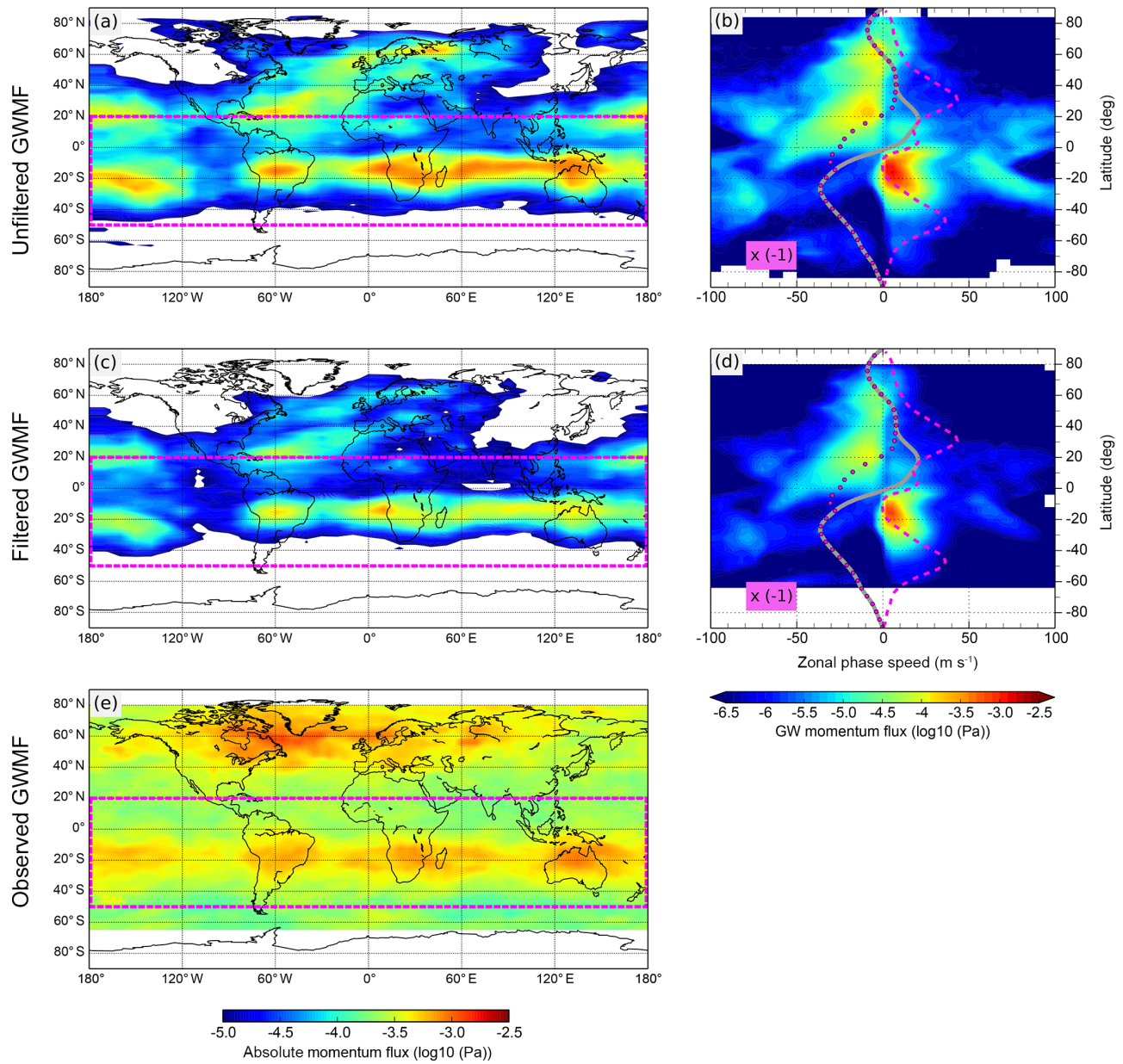

GW momentum flux $(\log 10(\mathrm{~Pa}))$

Figure 7. Horizontal distribution of (a) unfiltered absolute GWMF and (c) filtered absolute GWMF in comparison with (e) horizontal distribution of observed absolute GWMF. Panel (b) shows phase speed spectrum of unfiltered zonal GWMF (absolute values) and (d) shows phase speed spectrum of filtered zonal GWMF (absolute values). In phase speed spectra, GWMF values associated with negative values of phase speed (on the left-hand side) are multiplied with -1 . Results are shown for January 2006 at $40 \mathrm{~km}$ altitude. Simulations were performed using MERRA data. For details see text.

the center of the peak at about $5 \mathrm{~ms}^{-1}$. At higher phase speeds (beyond $40-50 \mathrm{~m} \mathrm{~s}^{-1}$ ), two minor peaks in both eastward and westward directions are found. The GWMF associated with these minor peaks is about 2 orders of magnitude lower in comparison with the main peak. In mid- and highlatitude regions, high GWMF values are mainly associated with westward phase speeds varying from several $\mathrm{ms}^{-1}$ to about $40 \mathrm{~m} \mathrm{~s}^{-1}$. Figure $6 \mathrm{~d}$ shows the phase speed spectrum of filtered GWMF. The observational filter in this case reduces GWMF magnitude but almost does not impact the spectrum structure.

The effect of wind filtering can also be found in the phase speed spectrum. This effect occurs when a wave encounters the critical level, i.e., where the background wind equals the phase speed of the wave. In this case, the intrinsic phase speed and thus the vertical wavelength approach zero caus- ing saturation and the release of GWMF. In Fig. $6 \mathrm{~b}$ and d, GWMF are mainly found in the areas where GW phase speed is larger than maximal zonal mean of zonal wind (magenta plus line) or lower than minimal zonal mean of zonal wind (magenta dotted line). A small amount of GWMF still can be found in between these two lines because of the following: (a) these lines only indicate the zonal mean of the zonal wind and thus waves may be able to propagate due to local variations and (b) many waves also have a meridional component. Still the findings indicate that filtering is dominated by the variation of the zonal wind.

For January 2006 at $40 \mathrm{~km}$ altitude, the horizontal band of high GWMF values in the summer subtropics becomes narrower (more concentrated around latitude of $\sim 15^{\circ} \mathrm{S}$ ) and is slightly shifted poleward. The magnitude of GWMF decreases strongly with altitude, as can be seen by comparing 
Jul 2006, $z=25 \mathrm{~km}$
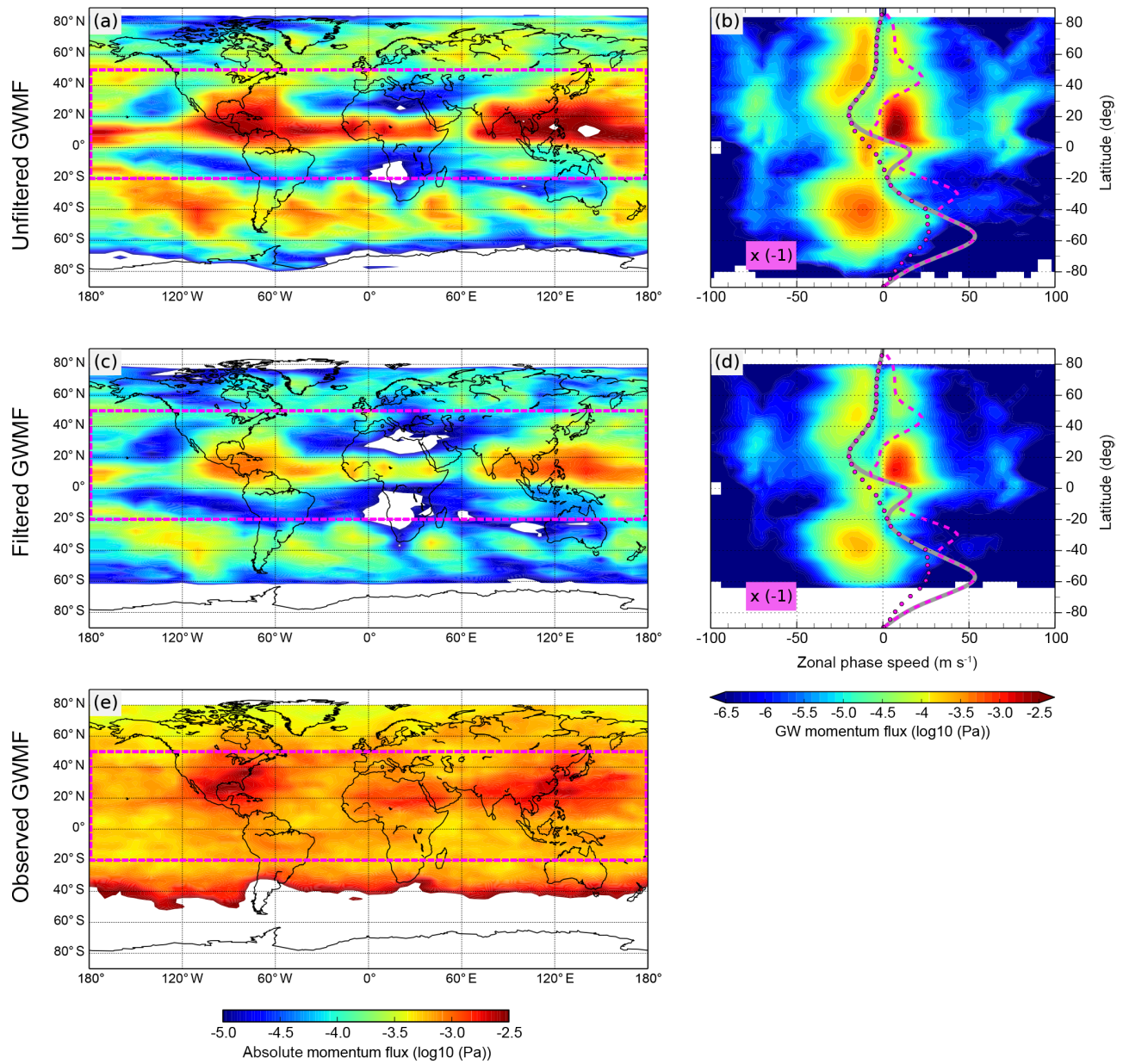

Figure 8. Horizontal distribution of (a) unfiltered absolute GWMF and (c) filtered absolute GWMF in comparison with (e) horizontal distribution of observed absolute GWMF. Panel (b) shows phase speed spectrum of unfiltered zonal GWMF (absolute values) and (d) shows phase speed spectrum of filtered zonal GWMF (absolute values). In phase speed spectra, GWMF values associated with negative values of phase speed (on the left-hand side) are multiplied with -1 . Results are shown for July 2006 at $25 \mathrm{~km}$ altitude. Simulations were performed using MERRA data. For details see text.

Figs. 6a and 7a. This is also in agreement with the vertical cross section of absolute GWMF shown in Fig. 4a. A wind reversal at about $30 \mathrm{~km}$ altitude is likely the main reason for the reduced GWMF values close to the equator, or in other words, for narrowing the horizontal band of high GWMF values. The location of simulated and observed GWMF hot spots agrees well (cf. Fig. 7a, b, c). At $40 \mathrm{~km}$ altitude the measurements indicate that GWMF in the hot-spot regions, where the model results suggest deep convection as the dominant source, is enhanced by about 1 order of magnitude compared to the background regions. This is a stronger enhancement than at $25 \mathrm{~km}$ altitude (about half an order of magnitude) and indicates that the non-convective background is relatively less important at $40 \mathrm{~km}$.

Also the phase speed spectrum changes with altitude: the main peak of the spectrum at $40 \mathrm{~km}$ does not stretch over the equator as for $25 \mathrm{~km}$ but is limited only to the Southern Hemisphere. This change is according to the change of the maximal zonal wind, which is indicated by the magenta plus line. This line surrounds the main peak in the tropics. Another major difference of the phase speed spectrum at $40 \mathrm{~km}$ in comparison with the one at $25 \mathrm{~km}$ is the absence of the peak at mid- and high latitudes in the Southern Hemisphere at westward phase speeds ( 20 to $40^{\circ} \mathrm{S}$ ). This absence is again likely related to wind filtering as indicated by the magenta dotted lines for the difference in minimum zonal winds in Figs. $6 b$, d and $7 b, d$, respectively.

For July 2006 at $25 \mathrm{~km}$ altitude, unfiltered GWMF (Fig. 8a) shows high values over the Caribbean sea, central Africa and the Asian Monsoon region. Figure 8c shows filtered GWMF with the magnitude reduced significantly due to the observational filter. Comparison of filtered GWMF 
Jul 2006, $z=40 \mathrm{~km}$
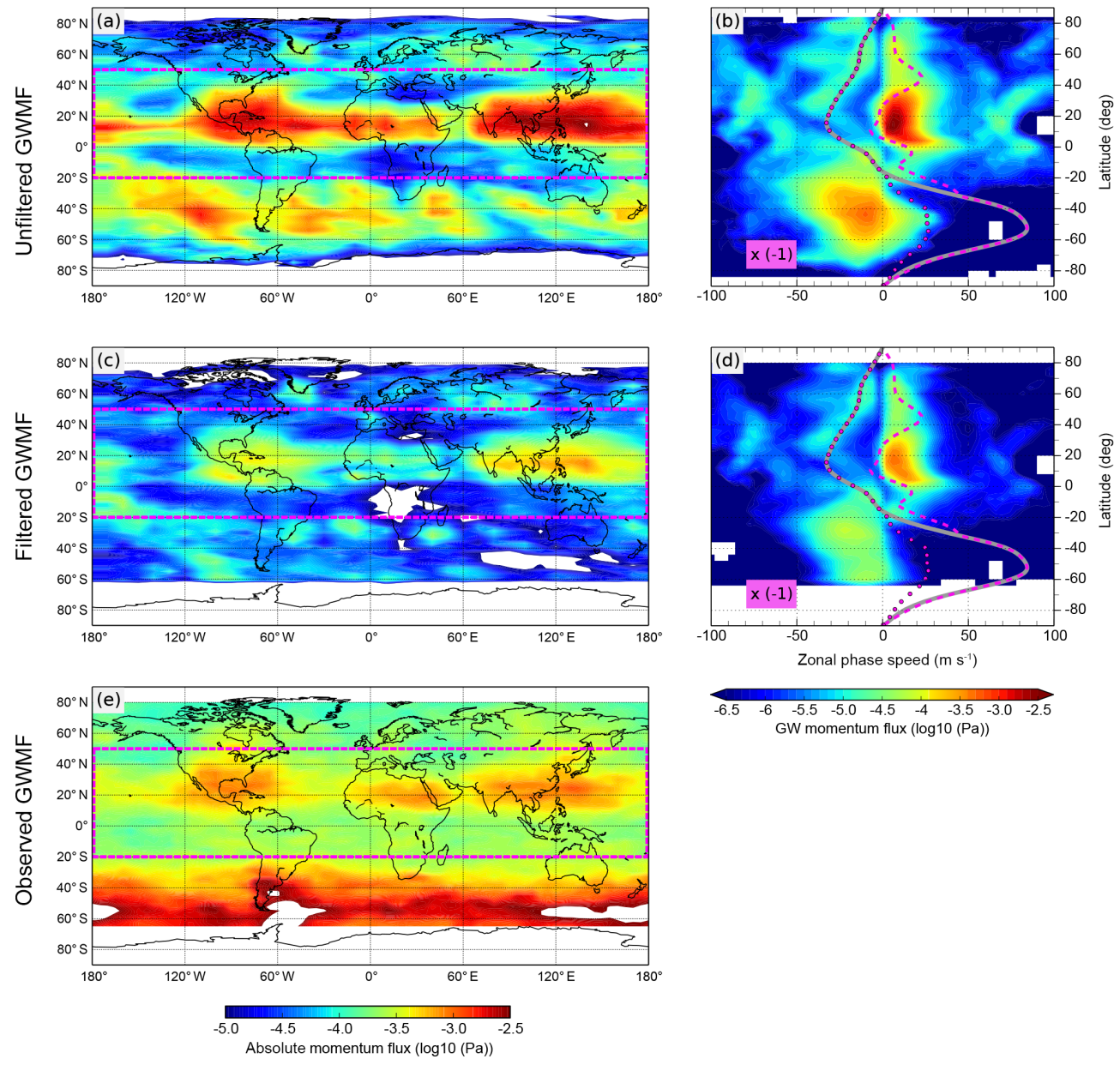

GW momentum flux $(\log 10(\mathrm{~Pa}))$

Figure 9. Horizontal distribution of (a) unfiltered absolute GWMF and (c) filtered absolute GWMF in comparison with (e) horizontal distribution of observed absolute GWMF. Panel (b) shows phase speed spectrum of unfiltered zonal GWMF (absolute values) and (d) shows phase speed spectrum of filtered zonal GWMF (absolute values). In phase speed spectra, GWMF values associated with negative values of phase speed (on the left-hand side) are multiplied with -1 . Results are shown for July 2006 at $40 \mathrm{~km}$ altitude. Simulations were performed using MERRA data. For details see text.

(Fig. 8c) and observed GWMF (Fig. 8e) shows quite a good agreement in locations of GMWF maxima. As seen before in the zonal means, however, the observed GWMF maxima are wider, i.e., extend further to the north. In addition, the model results also show GW excitation following the warm water currents of the Gulf Stream and the Kuroshio.

Similar to January 2006 at $25 \mathrm{~km}$ altitude, the phase speed spectra (Fig. 8b and d) show a main peak in the summer subtropics with eastward phase speeds from several $\mathrm{m} \mathrm{s}^{-1}$ to $\sim 30 \mathrm{~m} \mathrm{~s}^{-1}$. Moreover, two secondary peaks in the summer subtropics at high phase speeds (larger than $40-50 \mathrm{~m} \mathrm{~s}^{-1}$ ), which are $\sim 2.5$ orders of magnitude smaller in comparison with the main peak, are also found. The observational filter decreases the GWMF magnitude but almost does not alter the structure of the phase speed spectrum. This can be seen by comparing the spectrum structure shown Fig. $8 \mathrm{~b}$ and d.
Similar to the January case, the magnitude of GWMF decreases with altitude (Fig. 9). This decrease, however, is weaker than in January. In particular, there is no strong reduction of GWMF in the tropics, which narrows the region of strong GWMF between 25 and $40 \mathrm{~km}$, such as for January.

Concerning the phase speed spectrum at $40 \mathrm{~km}$ altitude (Fig. 9b, d), a major difference in comparison with the spectrum at $25 \mathrm{~km}$ is much lower GWMF at mid and high latitudes in the Northern Hemisphere (from $40-80^{\circ} \mathrm{N}$ ). This can be seen by comparing Figs. $8 \mathrm{~b}$, d with $9 \mathrm{~b}$, d. This reduction is likely related to the change of minimal zonal wind at this latitude range, which can be seen by comparing minimum zonal mean of zonal wind in Figs. 8b, d and 9b, d, respectively. 


\section{Summary and discussion}

In this study, the free parameters $\delta x$ and $\delta t$ representing the horizontal and temporal scales of the convection are derived; the strength and vertical structure of the heating are calculated from MERRA analysis data. The trajectory calculation for convective GWs generated by the CGWS scheme is performed using GROGRAT (Marks and Eckermann, 1995; Eckermann and Marks, 1997). For comparison with HIRDLS observations, a comprehensive observational filter (Trinh et al., 2015) is applied. The observed spectra can be well reproduced in terms of spectral shape and location of the peak by super-imposing four scale sets. The spectral shape of GWMF in the summer subtropics is different for January and July. Matching of simulated and observed spectra can only be achieved by different combinations of scale sets of the convective source indicating that this is an effect of the source properties rather than of the propagation conditions or observational filter. We considered 3 different years and found that in the Southern Hemisphere, source characteristics of the GWs cause consistently longer horizontal wavelengths. We also found a modulation of the spectrum due to a modulation of the propagation conditions by the QBO. This modulation of the spectrum can be reproduced using the same set of CGW source parameters during different years.

We used the parameters determined from the spectra and considered the contribution of these waves to the momentum balance by calculating zonal mean cross sections of absolute GWMF and its vertical gradients and compared them to respective observed quantities. The approach is limited by the fact that we have to use globally the CGW scheme parameters estimated for the subtropics, which is the only observational constraint available. The zonal average of filtered simulated GWMF is consistent with observed GWMF in the summer subtropics in both structure as well as magnitude. Applying the observational filter to the model, we find that in the mid-stratosphere in regions of wind shear, slow GWs are refracted to very short vertical wavelength. Consequentially, these waves cannot pass our observational filter and remain invisible whilst dissipating and exerting GWD at the location closely above the altitude where they become invisible to the instrument. Close to the stratopause waves of longer vertical wavelengths from all propagation directions reach saturation amplitudes and dissipate, in some cases without exerting much net drag. Similar to the absolute GWMF, the vertical gradient of filtered GWMF agrees well with the observed vertical gradient. Values of simulated zonal drag $X$ are of the same order as the expected GW driving of the QBO (Ern et al., 2014). This indicates that GWs from convection organized at scales of the order of $100 \mathrm{~km}$ are important for driving the QBO.

Horizontal distributions of absolute unfiltered and filtered GWMF are also presented in this work. These horizontal distributions show a good agreement with observed horizontal distributions in the structure as well as the magnitude. Main convection hot spots are well reproduced. We also showed the GWMF spectra in terms of zonal phase speed and latitude. These spectra show a main peak in the tropics and summer subtropics associated with eastward phase speeds between several $\mathrm{ms}^{-1}$ and about $30 \mathrm{~m} \mathrm{~s}^{-1}$. As CGWs are commonly believed to dominate the tropics and subtropics, these phase speed spectra are expected to match respective observations of the same regions.

The vertical gradient of absolute GWMF provided by measurements is not always an indication of drag. At places where GWs have grown to reach saturation amplitudes contributions from different propagation directions cancel each other. We see such a case, for instance, in the southern subtropics around the stratopause in January. In addition, waves may leave the observational filter but do not break. For instance, it was argued by Alexander (2015) that in this way the comparison of vertical gradients of observed absolute GWMF with a momentum balance of the QBO shown by Ern et al. (2014) is not meaningful. The spectra inferred in this study show that zonal wind filtering of GWMF occurs for slow phase speed waves and in a very similar way for unfiltered and filtered simulations. Accordingly, in the zonal means there is a large similarity between simulated $P$ (the quantity corresponding to observations) and the absolute values of simulated drag $Q$. The only effect we can find is that waves first leave the observational filter and break soon after above, which shifts the observed "drag" downward in comparison to the real drag, an effect which was already discussed by Ern et al. (2014). Regarding wave saturation effects, it has been discussed by Ern et al. (2015) that the situation becomes more complicated if wave saturation apart from critical levels occurs. In this case, additional information about the GW spectrum may be required (for example, like pre-filtering of the GW spectrum by the winds at lower altitudes) to correctly interpret vertical gradients of observed absolute GWMF.

Due to the limitations of current global observations, the synergetic use of physics-based models, observational filter and observations using both absolute values of GWMF and its vertical gradient is currently the most promising way to infer the true properties of GWs in the atmosphere. GWs from single convective cells with horizontal scales of a few kilometers cannot be constrained by limb sounder data and exist in parallel as studies using different instruments show (Choi et al., 2009, 2012). The GWs exited by such events are clearly subgrid to global models and need to be parameterized, but also larger scale CGWs from organized convection may not well be represented depending on the convection parameterization (Ricciardulli and Garcia, 2000; Kim et al., 2007; Preusse et al., 2014) and would in this case need to be parameterized, even if the scales of potentially resulting GWs could be resolved by the dynamical core of the model. 


\section{Data availability}

The data used in this study are open access and are provided by the National Aeronautics and Space Administration (NASA). These data are available at http: //disc.sci.gsfc.nasa.gov/. The data used in the current study are: tavg3_3d_cld_Cp: MERRA 3D IAU Diagnostic, Cloud Properties, Time average 3-hourly (GMAO, 2008a), tavg3_3d_mst_Cp: MERRA 3D IAU Diagnostic, Moist Physics, Time average 3-hourly (GMAO, 2008b), tavg3_3d_udt_Cp: MERRA 3D IAU Tendency, Wind Components, Time average 3-hourly (GMAO, 2008c), tavg3_3d_tdt_Cp: MERRA 3D IAU Tendency, Temperature, Time average 3-hourly (GMAO, 2008d), and HIRDLS/Aura Level 2 Geophysical Parameters (Gille and Gray, 2012). 
Appendix A: Interannual variability and consistent differences between Southern and Northern Hemisphere

In this section, we address how the interannual variation of spectra compares to the difference between the spectra for the two hemispheres. Spectra are calculated for the deep convection regions defined by Ern and Preusse (2012) and shown in Fig. 2. For boreal summer (June, July, August) spectra are calculated for the regions marked in red, for austral summer (December, January, February) spectra are calculated for the regions marked in green. Figure A1a, b, c show spectra averaged for boreal summer for 2005, 2006, 2007 respectively; panels d, e, f show spectra averaged for austral summer for 2005/6, 2006/7, 2007/8. Therefore, each row in Fig. A1 can be considered as the spectra of the different hemispheres of the same year.

From Fig. A1, it can be seen that regarding the magnitude of momentum fluxes, there is considerable year-to-year variability in the Northern Hemisphere and weaker variability in the Southern Hemisphere. Time series of GW momentum flux from SABER (Ern et al., 2011) indicate that these variations are related to the QBO. Considering all three rows, there is a consistent difference in the overall shape of the spectral distributions for the Northern and Southern Hemisphere, respectively. In addition, for the Northern Hemisphere, the peak vertical wavelength is slightly longer in years of stronger momentum flux. On the other hand, for a given hemisphere, the peak horizontal wavelength is very similar for different years.

In order to show the variation of the horizontal wavelength more clearly, we produced line plots of the horizontal spectral distribution. Normalized GWMF spectra at a vertical wavelength of $9 \mathrm{~km}$ are shown in Fig. A2. The value of $9 \mathrm{~km}$ is chosen because for all spectra $9 \mathrm{~km}$ is close to the peak value. In Fig. A2, the solid lines show the spectra for Northern Hemisphere and the dashed lines show spectra for Southern Hemisphere. In particular, solid blue, green, and red lines show spectra averaged for boreal summer (JuneAugust) for 2005, 2006, 2007 respectively. Dashed blue, green, and red lines show spectra averaged for austral summer (December-February) for 2005/6, 2006/7, 2007/8. The differences among solid lines or among dashed lines are smaller than the difference between these two groups. The spectra for the Southern Hemisphere (dashed lines) are persistently peaking at lower horizontal wavenumbers (longer horizontal wavelengths) compared to the Northern Hemisphere spectra.

We now apply the scale sets that we found based on observations of 2006 to simulate spectra of the different hemispheres for different years. The simulated spectra at $25 \mathrm{~km}$ altitude are shown in Fig. A3. In Fig. A3, the color code shows the simulated GWMF spectrum and the dashed contour lines show the respective observed spectrum. As Fig. A3 shows, the scale sets selection based on observations of 2006 can reproduce the observed spectra of the same hemisphere for other years quite well. It is noteworthy that the yearto-year variability is well captured by these simulations (cf. Figs. A3 and A1). This year-to-year variation is particularly visible in the Northern Hemisphere, presumably associated with the QBO. An exception is the Southern Hemisphere in 2007 which exaggerates the interannual variations in the simulation (cf. Fig. A3e). The disagreement for the Southern Hemisphere, 2007 therefore will be the subject of further investigation.

The year-to-year variability, in particular for the Northern Hemisphere, is reproduced using only one set of GW source parameters for all years. This indicates that the variability is introduced by the QBO via the variation of propagation conditions and not by a variation of the source characteristic. In particular, this is consistent with the fact that the vertical wavelength changes between different years but not the horizontal wavelength.

In addition, we tested whether simulations based on the Southern Hemisphere setup of selected scales can reproduce observed Northern Hemisphere spectra, i.e., the setup of the opposite (wrong) hemisphere is used for this simulation. As an example, this simulation was carried out for July 2006. The results are shown in Fig. A4. The simulations comprise effects of the observational filter and modulation by the background wind. The fact that using the setup of Southern Hemisphere cannot reproduce the observed spectrum of the Northern Hemisphere is therefore an indication that the difference in the observed spectra is not caused merely by observational filter effects, i.e., that there is a real difference in the $\mathrm{GW}$ source characteristics (scales) for the two hemispheres. 
Northern Hemisphere Southern Hemisphere
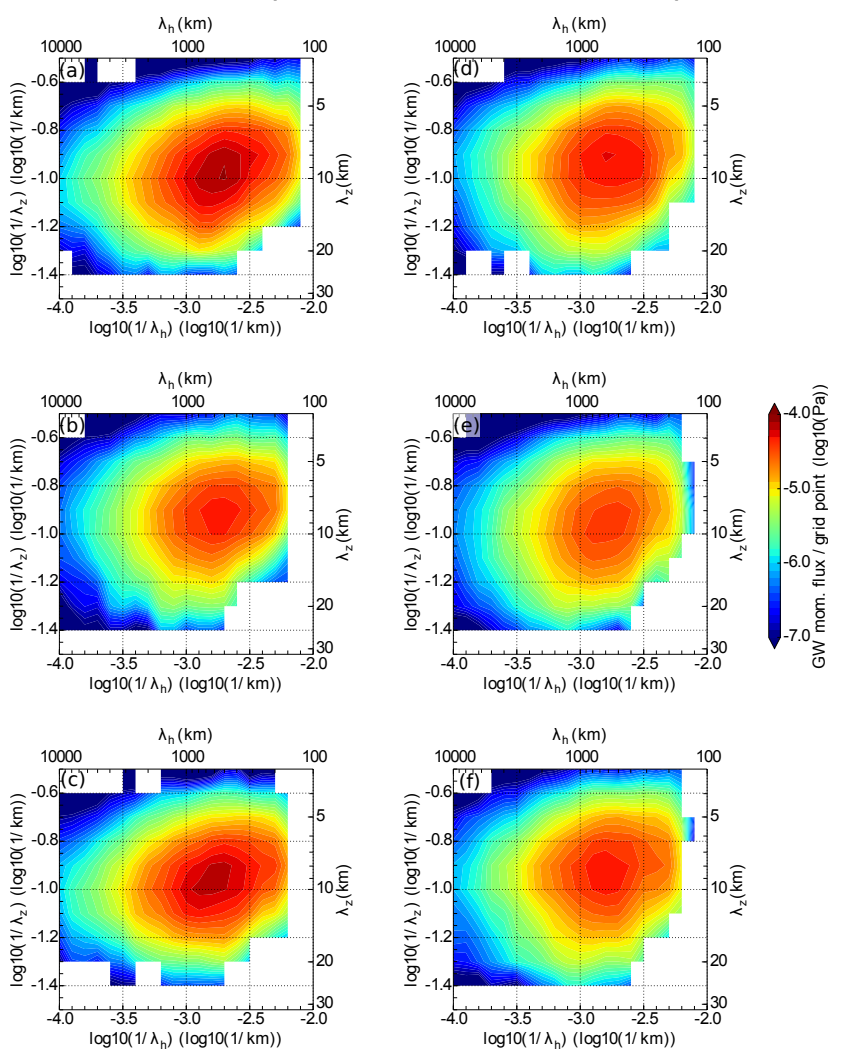

Figure A1. Observed spectra for different hemispheres for 3 consecutive years. Panels $(\mathbf{a}, \mathbf{b}, \mathbf{c})$ Show spectra averaged for boreal summer (June-August) for 2005, 2006, 2007 respectively; panels $(\mathbf{d}, \mathbf{e}, \mathbf{f})$ show spectra averaged for austral summer (DecemberFebruary) for 2005/6, 2006/7, 2007/8. All spectra are averaged over three regions of deep convection of each hemisphere as shown in Fig. 2.

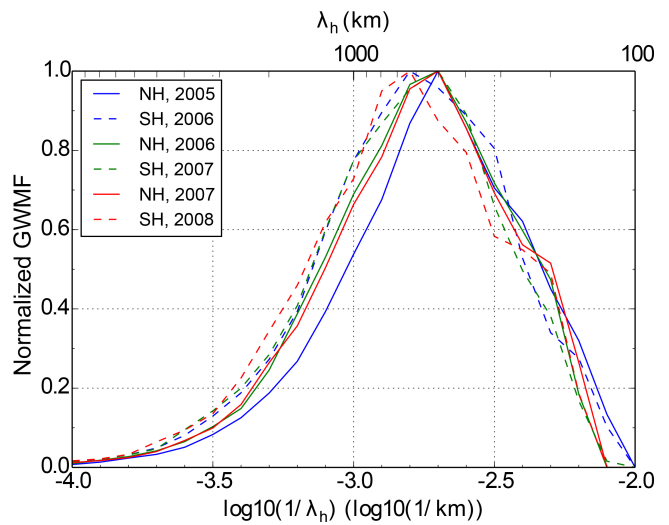

Figure A2. Observed normalized GWMF spectra at vertical wavelength $\lambda_{z}=9 \mathrm{~km}$ for different hemispheres for 3 consecutive years. Solid blue, green, red lines show spectra averaged for boreal summer (June-August) for 2005, 2006, 2007 respectively. Dashed blue, green, red lines show spectra averaged for austral summer (December-February) for 2005/6, 2006/7, 2007/8.
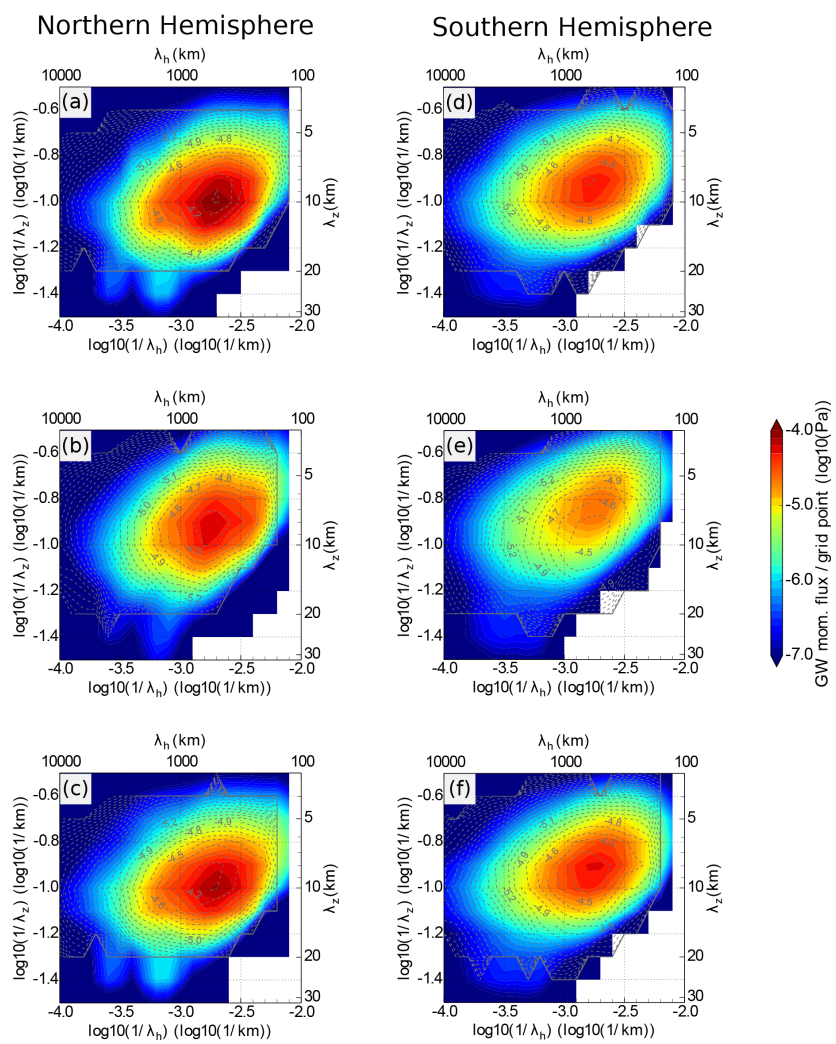

Figure A3. Filtered simulated GWMF spectra for different hemispheres for 3 consecutive years. Panels $(\mathbf{a}, \mathbf{b}, \mathbf{c})$ show spectra for July 2005, 2006, 2007 respectively; panels (d, e, f) show spectra for January 2006, 2007, 2008. All spectra are averaged over three regions of deep convection of each hemisphere as shown in Fig. 2

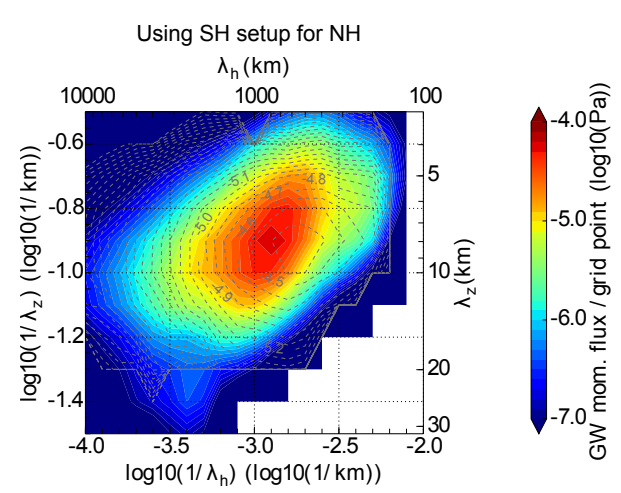

Figure A4. Filtered simulated GWMF spectra for Northern Hemisphere (July) 2006, run by using the set of scales selected for Southern Hemisphere (January 2006). 
Acknowledgements. This work was funded in part by the Deutsche Forschungsgemeinschaft (DFG) via the project MS-GWaves/SV (PR 919/4-1). H.-Y. Chun and M.-J. Kang were supported by the Korea Meteorological Administration (KMA) Research and Development Program under Grant KMIPA 2015-6160.

The article processing charges for this open-access

publication were covered by a Research

Centre of the Helmholtz Association.

Edited by: P. Haynes

\section{References}

Alexander, M. J.: Global and seasonal variations in threedimensional gravity wave momentum flux from satellite limbsounding temperatures, Geophys. Res. Lett., 42, 6860-6867, doi:10.1002/2015GL065234, 2015.

Alexander, M. J. and Ortland, D. A.: Equatorial waves in High Resolution Dynamics Limb Sounder (HIRDLS) data, J. Geophys. Res., 115, D24111, doi:10.1029/2010JD014782, 2010.

Alexander, M. J. and Rosenlof, K. H.: Gravity-wave forcing in the stratosphere: Observational constraints from the Upper Atmosphere Research Satellite and implications for parameterization in global models, J. Geophys. Res., 108, 4597, doi:10.1029/2003JD003373, 2003.

Alexander, M. J., Gille, J., Cavanaugh, C., Coffey, M., Craig, C., Dean, V., Eden, T., Francis, G., Halvorson, C., Hannigan, J., Khosravi, R., Kinnison, D., Lee, H., Massie, S., and Nardi, B.: Global estimates of gravity wave momentum flux from High Resolution Dynamics Limb Sounder (HIRDLS) observations, J. Geophys. Res., 113, D15S18, doi:10.1029/2007JD008807, 2008.

Alexander, M. J., Geller, M., McLandress, C., Polavarapu, S., Preusse, P., Sassi, F., Sato, K., Eckermann, S. D., Ern, M., Hertzog, A., Kawatani, Y., Pulido, M., Shaw, T., Sigmond, M., Vincent, R., and Watanabe, S.: Recent developments in gravity wave effects in climate models, and the global distribution of gravity wave momentum flux from observations and models, Q. J. Roy. Meteorol. Soc., 136, 1103-1124, doi:10.1002/qj.637, 2010.

Andrews, D. G., Holton, J. R., and Leovy, C. B.: Middle Atmosphere Dynamics, Vol. 40 of International Geophysics Series, Academic Press, 1987.

Beres, J. H., Alexander, M. J., and Holton, J. R.: A method of specifying the gravity wave spectrum above convection based on latent heating properties and background wind, J. Atmos. Sci., 61, 324-337, 2004.

Choi, H. J. and Chun, H. Y.: Momentum flux spectrum of convective gravity waves. Part I: An update of a parameterization using mesoscale simulation, J. Atmos. Sci, 68, 739-759, doi:10.1175/2010JAS3552.1, 2011.

Choi, H.-J., Chun, H.-Y., and Song, I.-S.: Gravity wave temperature variance calculated using the ray-based spectral parameterization of convective gravity waves and its comparison with Microwave Limb Sounder observations, J. Geophys. Res., 114, D08111, doi:10.1029/2008JD011330, 2009.

Choi, H.-J., Chun, H.-Y., Gong, J., and Wu, D. L.: Comparison of gravity wave temperature variances from ray-based spectral parameterization of convective gravity wave drag with AIRS observations, J. Geophys. Res., 117, D05115, doi:10.1029/2011JD016900, 2012.

Chun, H.-Y. and Baik, J.-J.: Momentum Flux by Thermally Induced Internal gravity Waves and Its Approximation for Large-Scale Models, J. Atmos. Sci., 55, 3299-3310, 1998.

Chun, H.-Y. and Baik, J.-J.: An Updated Parameterization of Convectively Forced Gravity Wave Drag for Use in Large-Scale Models, J. Atmos. Sci., 59, 1006-1017, 2002.

Dee, D. P., Uppala, S. M., Simmons, A. J., Berrisford, P., Poli, P., Kobayashi, S., Andrae, U., Balmaseda, M. A., Balsamo, G., Bauer, P., Bechtold, P., Beljaars, A. C. M., van de Berg, L., Bidlot, J., Bormann, N., Delsol, C., Dragani, R., Fuentes, M., Geer, A. J., Haimberger, L., Healy, S. B., Hersbach, H., Holm, E. V., Isaksen, L., Kallberg, P., Koehler, M., Matricardi, M., McNally, A. P., Monge-Sanz, B. M., Morcrette, J. J., Park, B. K., Peubey, C., de Rosnay, P., Tavolato, C., Thepaut, J. N., and Vitart, F.: The ERA-Interim reanalysis: configuration and performance of the data assimilation system, Q. J. Roy. Meteor. Soc., 137, 553-597, doi:10.1002/qj.828, 2011.

Dunkerton, T. J.: The role of gravity waves in the quasi-biennial oscillation, J. Geophys. Res., 102, 26053-26076, 1997.

Eckermann, S. D. and Marks, C. J.: GROGRAT: a New Model of the Global propagation and Dissipation of Atmospheric Gravity Waves, Adv. Space Res., 20, 1253-1256, 1997.

Ern, M. and Preusse, P.: Quantification of the contribution of equatorial Kelvin waves to the QBO wind reversal in the stratosphere, Geophys. Res. Lett., 36, L21801, doi:10.1029/2009GL040493, 2009.

Ern, M. and Preusse, P.: Gravity wave momentum flux spectra observed from satellite in the summertime subtropics: Implications for global modeling, Geophys. Res. Lett., 39, L15810, doi:10.1029/2012GL052659, 2012.

Ern, M., Preusse, P., Alexander, M. J., and Warner, C. D.: Absolute values of gravity wave momentum flux derived from satellite data, J. Geophys. Res., 109, D20103, doi:10.1029/2004JD004752, 2004.

Ern, M., Preusse, P., and Warner, C. D.: Some experimental constraints for spectral parameters used in the Warner and McIntyre gravity wave parameterization scheme, Atmos. Chem. Phys., 6, 4361-4381, doi:10.5194/acp-6-4361-2006, 2006.

Ern, M., Preusse, P., Gille, J. C., Hepplewhite, C. L., Mlynczak, M. G., Russell III, J. M., and Riese, M.: Implications for atmospheric dynamics derived from global observations of gravity wave momentum flux in stratosphere and mesosphere, J. Geophys. Res., 116, D19107, doi:10.1029/2011JD015821, 2011.

Ern, M., Preusse, P., Kalisch, S., Kaufmann, M., and Riese, M.: Role of gravity waves in the forcing of quasi two-day waves in the mesosphere: An observational study, J. Geophys. Res.-Atmos., 118, 3467-3485, doi:10.1029/2012JD018208, 2013.

Ern, M., Ploeger, F., Preusse, P., Gille, J. C., Gray, L. J., Kalisch, S., Mlynczak, M. G., Russell, J. M., and Riese, M.: Interaction of gravity waves with the QBO: A satellite perspective, J. Geophys. Res.-Atmos., 119, 2329-2355, doi:10.1002/2013JD020731, 2014.

Ern, M., Preusse, P., and Riese, M.: Driving of the SAO by gravity waves as observed from satellite, Ann. Geophys., 33, 483-504, doi:10.5194/angeo-33-483-2015, 2015. 
Evan, S., Alexander, M. J., and Dudhia, J.: WRF simulations of convectively generated gravity waves in opposite QBO phases, J. Geophys. Res., 117, D12117, doi:10.1029/2011JD017302, 2012.

Fritts, D. and Alexander, M.: Gravity wave dynamics and effects in the middle atmosphere, Rev. Geophys., 41, 1003, doi:10.1029/2001RG000106, 2003.

Fritts, D. C. and Rastogi, P. K.: Convective and dynamical instabilities due to gravity wave motions in the lower and middle atmosphere: theory and observations, Radio Sci., 20, 1247-1277, 1985.

Geller, M. A., Alexander, M. J., Love, P. T., Bacmeister, J., Ern, M., Hertzog, A., Manzini, E., Preusse, P., Sato, K., Scaife, A. A., and Zhou, T.: A comparison between gravity wave momentum fluxes in observations and climate models, J. Climate, 26, 6383-6405, doi:10.1175/JCLI-D-12-00545.1, 2013.

Gille, J. and Gray, L. J.: HIRDLS/Aura Level 2 Geophysical Parameters (on a pressure grid), version 007, Greenbelt, MD, USA, NASA Goddard Earth Science Data and Information Services Center (GES DISC), available at: doi:10.5067/AURA/HIRDLS/DATA201 (last access: 25 April 2015), 2012.

Global Modeling and Assimilation Office (GMAO): tavg3_3d_cld_Cp: MERRA 3D IAU Diagnostic, Cloud Properties, Time average 3-hourly (1.25x1.25L42), version 5.2.0, Greenbelt, MD, USA, Goddard Space Flight Center Distributed Active Archive Center (GSFC DAAC), available at: doi:10.5067/TW0W0RC88E9A (last access: 15 January 2013), 2008a.

Global Modeling and Assimilation Office (GMAO): tavg3_3d_mst_Cp: MERRA 3D IAU Diagnostic, Moist Physics, Time average 3-hourly (1.25x1.25L42), version 5.2.0, Greenbelt, MD, USA, Goddard Space Flight Center Distributed Active Archive Center (GSFC DAAC), available at: doi:10.5067/03WVRVVXCHZX (last access: 15 January 2013), 2008b.

Global Modeling and Assimilation Office (GMAO): tavg3_3d_udt_Cp: MERRA 3D IAU Tendency, Wind Components, Time average 3-hourly $(1.25 \times 1.25 \mathrm{~L} 42)$, version 5.2.0, Greenbelt, MD, USA, Goddard Space Flight Center Distributed Active Archive Center (GSFC DAAC), available at: doi:10.5067/BVOFEHG7TR07 (last access: 18 January 2013), 2008c.

Global Modeling and Assimilation Office (GMAO): tavg3_3d_tdt_Cp: MERRA 3D IAU Tendency, Temperature, Time average 3-hourly (1.25x1.25L42), version 5.2.0, Greenbelt, MD, USA, Goddard Space Flight Center Distributed Active Archive Center (GSFC DAAC), available at: doi:10.5067/RP02UMM6LH1B (last access: 18 January 2013), 2008d.

Jia, J. Y., Preusse, P., Ern, M., Chun, H.-Y., Gille, J. C., Eckermann, S. D., and Riese, M.: Sea surface temperature as a proxy for convective gravity wave excitation: a study based on global gravity wave observations in the middle atmosphere, Ann. Geophys., 32, 1373-1394, doi:10.5194/angeo-32-1373-2014, 2014.

Jiang, J., Wang, B., Goya, K., Hocke, K., Eckermann, S., Ma, J., Wu, D., and Read, W.: Geographical distribution and interseasonal variability of tropical deep convection: UARS MLS observations and analyses, J. Geophys. Res. Atmos., 109, D03111, doi:10.1029/2003JD003756, 2004.
Kershaw, R.: Parametrization of momentum transport by convectively generated gravity waves, Q. J. Roy. Meteor. Soc., 121, 1023-1040, doi:10.1002/qj.49712152505, 1995.

Khouider, B. and Moncrieff, M. W.: Organized Convection Parameterization for the ITCZ, J. Atmos. Sci., 72, 3073-3096, doi:10.1175/JAS-D-15-0006.1, 2015.

Kilpatrick, T. J. and Xie, S.-P.: ASCAT observations of downdrafts from mesoscale convective systems, Geophys. Res. Lett., 42, 1951-1958, doi:10.1002/2015GL063025, 2015.

Kim, J.-E. and Alexander, M. J.: Tropical Precipitation Variability and Convectively Coupled Equatorial Waves on Submonthly Time Scales in Reanalyses and TRMM, J. Climate, 26, 30133030, doi:10.1175/JCLI-D-12-00353.1, 2013.

Kim, S.-Y., Chun, H.-Y., and Baik, J.-J.: Sensitivity of typhooninduced gravity waves to cumulus parameterizations, Geophys. Res. Lett., 34, L15814, doi:10.1029/2007GL030592, 2007.

Kim, Y.-H. and Chun, H.-Y.: Contributions of equatorial wave modes and parameterized gravity waves to the tropical QBO in HadGEM2, J. Geophys. Res.-Atmos., 120, 1065-1090, doi:10.1002/2014JD022174, 2015.

Kim, Y.-J., Eckermann, S. D., and Chun, H.-Y.: An overview of the past, present and future of gravity-wave drag parameterization for numerical climate and weather prediction models - Survey article, Atmos.-Ocean, 41, 65-98, doi:10.3137/ao.410105, 2003.

Leena, P., Venkat Ratnam, M., and Krishna Murthy, B.: Inertia gravity wave characteristics and associated fluxes observed using five years of radiosonde measurements over a tropical station, J. Atmos. Sol.-Terr. Phy., 84-85, 37-44, doi:10.1016/j.jastp.2012.05.004, 2012.

Lehmann, C. I., Kim, Y.-H., Preusse, P., Chun, H.-Y., Ern, M., and Kim, S.-Y.: Consistency between Fourier transform and smallvolume few-wave decomposition for spectral and spatial variability of gravity waves above a typhoon, Atmos. Meas. Tech., 5, 1637-1651, doi:10.5194/amt-5-1637-2012, 2012.

Lighthill, M. J.: Waves in fluids, Comm. Pure Appl. Math., 20, $267-$ 293, doi:10.1002/cpa.3160200204, 1967.

Lindzen, R. S.: Turbulence and Stress Owing to Gravity Wave and Tidal Breakdown, J. Geophys. Res., 86, 9707-9714, 1981.

Liu, C. and Zipser, E. J.: The global distribution of largest, deepest, and most intense precipitation systems, Geophys. Res. Lett., 42, 3591-3595, doi:10.1002/2015GL063776, 2015.

Marks, C. J. and Eckermann, S. D.: A three-dimensional nonhydrostatic ray-tracing model for gravity waves: formulation and preliminary results for the middle atmosphere, J. Atmos. Sci., 52, 1959-1984, 1995.

Matsuno, T.: A quasi one-dimensional model of the middle atmosphere circulation interacting with internal gravity waves, J. Meteorol. Soc. Jpn., 60, 215-226, 1982.

McIntyre, M. E.: Breaking waves and global scale chemical transport in the Earth's atmosphere, with spinoffs for the Sun's interior, Prog. Theor. Phys., 130, 137-166, 1998.

McLandress, C.: On the importance of gravity waves in the middle atmosphere and their parameterization in general circulation models, J. Atmos. Terr. Phy., 60, 1357-1383, 1998.

McLandress, C., Alexander, M. J., and Wu, D. L.: Microwave Limb Sounder observations of gravity waves in the stratosphere: A climatology and interpretation, J. Geophys. Res., 105, 1194711967, 2000. 
Pitteway, M. L. V. and Hines, C. O.: The viscous damping of atmospheric gravity waves, Can. J. Phys., 41, 1935-1948, doi:10.1139/p63-194, 1963.

Pramitha, M., Venkat Ratnam, M., Taori, A., Krishna Murthy, B. V., Pallamraju, D., and Vijaya Bhaskar Rao, S.: Evidence for tropospheric wind shear excitation of high-phase-speed gravity waves reaching the mesosphere using the ray-tracing technique, Atmos. Chem. Phys., 15, 2709-2721, doi:10.5194/acp-15-27092015, 2015.

Preusse, P., Dörnbrack, A., Eckermann, S. D., Riese, M., Schaeler, B., Bacmeister, J. T., Broutman, D., and Grossmann, K. U.: Space-based measurements of stratospheric mountain waves by CRISTA, 1. Sensitivity, analysis method, and a case study, J. Geophys. Res., 107, 8178, doi:10.1029/2001JD000699, 2002.

Preusse, P., Ern, M., Bechtold, P., Eckermann, S. D., Kalisch, S., Trinh, Q. T., and Riese, M.: Characteristics of gravity waves resolved by ECMWF, Atmos. Chem. Phys., 14, 10483-10508, doi:10.5194/acp-14-10483-2014, 2014.

Ricciardulli, L. and Garcia, R. R.: The excitation of equatorial waves by deep convection in the NCAR Community Climate Model (CCM3), J. Atmos. Sci., 57, 3461-3487, 2000.

Rienecker, M. M., Suarez, M. J., Gelaro, R., Todling, R., Bacmeister, J., Liu, E., Bosilovich, M. G., Schubert, S. D., Takacs, L., Kim, G.-K., Bloom, S., Chen, J., Collins, D., Conaty, A., da Silva, A., Gu, W., Joiner, J., Koster, R. D., Lucchesi, R., Molod, A., Owens, T., Pawson, S., Pegion, P., Redder, C. R., Reichle, R., Robertson, F. R., Ruddick, A. G., Sienkiewicz, M., and Woollen, J.: MERRA: NASA's Modern-Era Retrospective Analysis for Research and Applications, J. Climate, 24, 3624-3648, doi:10.1175/JCLI-D-11-00015.1, 2011.
Rind, D., Suozzo, R., Balachandran, N. K., Lacis, A., and Russell, G.: The GISS Global Climate-Middle Atmosphere Model. Part I: Model Structure and Climatology, J. Atmos. Sci., 45, 329-370, doi:10.1175/1520-0469(1988)045<0329:TGGCMA>2.0.CO;2, 1988.

Song, I. S. and Chun, H. Y.: Momentum flux spectrum of convectively forced internal gravity waves and its application to gravity wave drag parameterization. Part I: theory, J. Atmos. Sci., 62, 107-124, 2005.

Song, I.-S., Chun, H.-Y., and Lane, T. P.: Generation Mechanisms of Convectively Forced Internal Gravity Waves and Their Propagation to the Stratosphere, J. Atmos. Sci., 60, 1960-1980, 2003.

Trinh, Q. T., Kalisch, S., Preusse, P., Chun, H.-Y., Eckermann, S. D., Ern, M., and Riese, M.: A comprehensive observational filter for satellite infrared limb sounding of gravity waves, Atmos. Meas. Tech., 8, 1491-1517, doi:10.5194/amt-8-1491-2015, 2015.

Wright, J. S. and Fueglistaler, S.: Large differences in reanalyses of diabatic heating in the tropical upper troposphere and lower stratosphere, Atmos. Chem. Phys., 13, 9565-9576, doi:10.5194/acp-13-9565-2013, 2013.

Zhu, X.: A New Theory of the Saturated Gravity Wave Spectrum for the Middle Atmosphere, J. Atmos. Sci., 51, 3615-3626, 1994. 